\title{
LA INTERPRETACIÓN DE LA RESOLUCIÓN DE CALIFICACIÓN AMBIENTAL
}

\section{THE INTERPRETATION OF AN ENVIRONMENTAL PERMIT}

\author{
Edesio Carrasco Quiroga* \\ JaVier Herrera Valverde**
}

\begin{abstract}
RESUMEN: El artículo propone criterios para la interpretación de las resoluciones de calificación ambiental (RCA). Para ello, los autores explican en sentido orgánico (quién), procedimental (cómo) y sustantivo (qué) la forma en que este acto administrativo debe interpretarse, basándose en argumentos de texto, contexto y en una nutrida jurisprudencia administrativa. Asimismo, el trabajo aborda, a partir del derecho administrativo, mecanismos de solución ante aspectos que comúnmente en una RCA requieren de una interpretación que otorgue seguridad en sus disposiciones.
\end{abstract}

Palabras clave: Interpretación, resoluciones de calificación ambiental, servicio de evaluación ambiental.

ABSTRACT: This paper proposes criteria for the interpretation of an environmental permit. The authors explain in organic (who), procedural (how) and substantive (what) sense, the way this administrative act must be interpreted based on the text, context, and in a large administrative rules. The paper also addresses, from administrative law, solutions in order to give certainty to the provisions of these environmental decisions.

Key words: Interpretation, Environmental Permit, Environmental Assessment Agency.

\section{INTRODUCCIÓN}

Al revisar una resolución de calificación ambiental (en adelante RCA) suelen encontrarse disposiciones respecto de las cuales existe duda o confusión. Ya sea porque un plan de manejo no especificó el plazo para su ejecución o no se determinó la metodología para monitorear un componente ambiental, lo concreto es que hay considerandos que abren un margen de apreciación para quién debe ejecutar el proyecto o verificar su cumplimiento.

Así, ante capítulos, párrafos o secciones de una RCA respecto de los cuales existe una legítima duda referida a lo mandado, permitido o prohibido, surge la necesidad de interpretar su contenido. Incluso, teniendo claridad de cómo debe ejecutarse lo autorizado y bajo qué términos, surgen a veces, por ejemplo, interpretaciones disímiles respecto al método para el control y seguimiento de una variable ambiental, el tipo de modelo de pronóstico a utilizar o el caudal que debe liberarse para cumplir con los requerimientos propios del ecosistema.

\footnotetext{
* Profesor de Derecho Ambiental, Pontificia Universidad Católica de Chile. Email: ecarrasc@uc.cl.

** Ayudante de Derecho Administrativo, Pontificia Universidad Católica de Chile. Email: jnherrer@uc.cl.
} 
En esos términos, útil es preguntarse si la ley $\mathrm{N}^{\circ} 19.300$, sobre Bases Generales del Medio Ambiente (en adelante la ley o ley $\mathrm{N}^{\circ}$ 19.300) contempla reglas respecto a la interpretación de una RCA. Y de ser así, si estas son suficientes para cumplir con dicha función. Ahora bien, si dichas normas son o no eficaces, lo cierto es que hay otras disposiciones legales, dispersas en nuestro ordenamiento jurídico, que también son necesarias para una interpretación correcta de una RCA, pues no debe olvidarse que esa autorización constituye un acto administrativo y como tal debe, igualmente, sujetarse a los cánones de interpretación propios de este tipo de actos.

Considerando la relevancia de un asunto como este, tanto para los titulares de una RCA, eventuales afectados con la ejecución de un proyecto y la propia Superintendencia de Medio Ambiente (en adelante SMA o la Superintendencia), que fiscaliza el cumplimiento de las normas, condiciones y medidas en ella contenidas, se hace imprescindible abordar jurídicamente este asunto y proponer mecanismos de solución que den certeza a quienes utilizan la RCA ya sea como un vehículo de desarrollo de proyectos o actividades o como un medio para la ejecución de políticas, planes o programas públicos.

\section{NORMATIVA APLICABLE}

La letra g) del artículo 81 de la ley dispone que corresponderá al Servicio de Evaluación Ambiental (SEA) “interpretar administrativamente las Resoluciones de Calificación Ambiental, previo informe del o los organismos con competencia en la materia específica que participaron de la evaluación, del Ministerio y la Superintendencia de Medio Ambiente, según corresponda”.

En iguales términos, en su inciso segundo la norma dispone que "cuando el instrumento señalado en el inciso anterior contuviese aspectos normados sometidos a las facultades de interpretación administrativa del organismo sectorial respectivo, el informe solicitado tendrá el carácter de vinculante para el Ministerio en relación a esa materia”.

La norma legal previamente descrita fue incorporada a través de la ley $\mathrm{N}^{\circ} 20.417$, la que además otorgó dicha atribución al Ministerio del Medio Ambiente (MMA) para interpretar administrativamente "las normas de calidad ambiental y de emisión, los planes de prevención y/o de descontaminación, previo informe del o los organismos con competencia en la materia específica y la Superintendencia del Medio Ambiente" (artículo 70 letra o) de la ley).

De esta forma, el legislador entregó a las autoridades ambientales descritas la atribución para interpretar actos administrativos que emanan de las potestades que en parte les han sido conferidas. Es decir, el Congreso Nacional ha delegado en los principales órganos de la institucionalidad ambiental la facultad para dilucidar o aclarar el correcto sentido y alcance de sus propios actos bajo el entendido de que son ellos quienes mejor conocen las consideraciones tenidas en cuenta al momento de dictarlos. Lo anterior, sin perjuicio de las atribuciones que la SMA tiene al momento de fiscalizar y sancionar incumplimientos que se detecten a dicha autorización, lo que obviamente implica un análisis interpretativo ${ }^{1}$.

\footnotetext{
${ }^{1}$ Artículos 2, 3, 35 y 38, entre otros, de la Ley Orgánica de la Superintendencia de Medio Ambiente, ley N ${ }^{\circ}$ 20.417. El propio Mensaje del proyecto de ley que reformó posteriormente a la institucionalidad ambiental, otor-
} 


\section{DISTINCIONES PREVIAS}

Así, la interpretación de una RCA puede darse bajo distintas circunstancias, teniendo cada una de ellas una finalidad distinta que el legislador ha delimitado. Entre ellas destacan, frecuentemente, las siguientes situaciones:

\section{a) Consulta de pertinencia}

Este tipo de interpretaciones se producen cuando se pide a la autoridad ambiental que se pronuncie respecto de si, en base a los antecedentes proporcionados por el peticionario, un proyecto o actividad debe someterse al Sistema de Evaluación de Impacto Ambiental (en adelante SEIA) ${ }^{2}$.

En iguales términos y para los efectos de este trabajo, dicha consulta puede formularse cuando un proyecto o actividad, que cuenta con una RCA, decide realizar cambios y debe definirse (interpretarse) si estos corresponden o no a una alteración de consideración a la RCA que aceptó o aprobó un proyecto o actividad. Es decir, debe determinarse si la realización de obras, acciones o medidas tendientes a intervenir o complementar un proyecto o actividad ya ejecutado, son o no de envergadura ${ }^{3}$.

Lo descrito anteriormente es frecuente, ya que lo que se evalúa y califica ambientalmente corresponde, muchas veces, a una ingeniería conceptual o básica que luego se va precisando en función de los contratos de construcción o licitación que permiten ejecutar, pero también modificar, en función de razones técnicas propias de la actividad o del lugar en que se emplaza el proyecto, lo aceptado o aprobado en abstracto, cuestión que también puede ocurrir por razones de derecho ${ }^{4}$.

La respuesta a dichas consultas constituye un acto administrativo de juicio ${ }^{5}$, expresando un punto de vista acerca de las materias respecto de las cuales se ha requerido una opinión.

Dejamos constancia que las "consultas de pertinencia" están reguladas en nuestra normativa ambiental ${ }^{6}$, y constituyen una expresión del derecho a petición que la Constitu-

\footnotetext{
gaba, originalmente, toda la atribución a la SMA para interpretar lo que hoy tanto el MMA (normas y planes) como el SEA (RCA) por ley interpretan (Mensaje Presidencial N³52-356, de 5 de junio de 2008).

2 En este sentido, Prieto (2013) p. 186, para quien las consultas de pertinencias de ingreso al SEIA se han constituido como una "práctica administrativa a través de los años, como especie de concreción específica del derecho a petición, donde el titular de un proyecto específico obtiene una respuesta formal de la autoridad competente frente a la consulta de si su proyecto debe ser evaluado ambientalmente o no".

3 Letra d) del artículo 2 del Reglamento del Sistema de Evaluación de Impacto Ambiental (RSEIA), Decreto Supremo $\mathrm{N}^{\circ}$ 95/01, de 21 de agosto de 2001.

4 Igualmente, una consulta de pertinencia puede realizarse no teniendo el proponente una RCA, sino dudas respecto de si determinadas obras o acciones requieren o no ser evaluadas ambientalmente de manera previa a su ejecución. No obstante, la respuesta a dicha consulta no tiene por objeto interpretar una RCA, sino determinar la aplicación concreta de un precepto legal contenido en la ley $\mathrm{N}^{\circ} 19.300$ o en su reglamento respectivo, a determinados hechos que el solicitante pretende realizar.

5 Véase lo dispuesto en el dictamen $\mathrm{N}^{\circ}$ 7.620, de 2013.

6 Véase lo dispuesto en el artículo 26 del D.S. No 40, de 2012, del Ministerio del Medio Ambiente, que aprueba el Reglamento del SEIA, próximo a entrar en vigencia, el cual señala que "Sin perjuicio de las fa-
} 
ción Política de la República (en adelante CPR) contempla en su artículo 19 N 14 y que la ley $\mathrm{N}^{\circ} 19.880$ recoge en su artículo 17 letra h), correspondiendo así a un derecho que le asiste a toda persona de solicitar a la administración ambiental información acerca de los "requisitos jurídicos o técnicos que las disposiciones vigentes impongan a los proyectos, actuaciones o solicitudes que se propongan realizar".

\section{b) Normas, condiciones y medidas}

En iguales términos, si la propia RCA no precisa la forma en que parte de sus normas, condiciones y medidas deben ejecutarse, el ejercicio interpretativo se hace necesario. Ante ello, la autoridad debiese indicar la forma en que debe comprenderse, en su real sentido y alcance, uno o más considerandos de una RCA que fijan un mandato respecto del cual existen vacíos, lagunas o imprecisiones, volviendo, así, sobre su propio acto a fin de establecer los contornos de una determinada disposición ${ }^{7}$.

\section{c) Revisión de la RCA}

Asimismo, en caso que una RCA pretenda ser revisada de oficio o a petición de parte en razón de que al "ejecutarse el proyecto las variables evaluadas y contempladas en el plan de seguimiento sobre las cuales fueron establecidas las condiciones o medidas, hayan variado sustantivamente en relación a lo proyectado o no se hayan verificado", también requiere de una acción interpretativa a la RCA a fin de determinar si concurren los supuestos de hecho para proceder a su revisión ${ }^{8}$.

\section{d) Refundido y sistematización}

El artículo 25 sexies de la ley dispone que cuando una RCA sea modificada por una o varias RCA, el SEA, de oficio o a petición del proponente, podrá establecer el texto refundido, coordinado y sistematizado de dicha resolución. Si bien esta atribución para

cultades de la Superintendencia para requerir el ingreso de un proyecto o actividad, los proponentes podrán dirigirse al Director Regional o Director Ejecutivo del Servicio, según corresponda, a fin de solicitar un pronunciamiento sobre si, en base a los antecedentes proporcionados al efecto, un proyecto o actividad, o su modificación, debe someterse al Sistema de Evaluación de Impacto Ambiental. La respuesta que emita el Servicio deberá ser comunicada a la Superintendencia”. Asimismo, lo dispuesto en el Ord. $\mathrm{N}^{\circ} 131.456$, de 12 de septiembre de 2013, de la Dirección Ejecutiva del SEA, que Imparte instrucciones sobre las consultas de pertinencia de ingreso al Sistema de Evaluación de Impacto Ambiental, el cual se encuentra disponible en http:// www.sea.gob.cl/archivos/instructivos/Instructivo_solicitudes_pertinencias.pdf.

7 La letra i) del artículo 2 de ley $N^{\circ} 19.300$ dispone que un Estudio de Impacto Ambiental debe proporcionar "antecedentes fundados para la predicción, identificación e interpretación de su impacto ambiental y describir la o las acciones que ejecutará para impedir o minimizar sus efectos significativamente adversos". De la norma transcrita se desprende que también los propios Estudios de Impacto Ambiental deben, previo a ser presentados, "interpretar" sus impactos y describir las acciones que llevarán a cabo para neutralizar sus efectos. Así, los propios proponentes deben hacer también un ejercicio interpretativo, determinando el sentido y alcance ex ante de los impactos que reconocen y de las medidas apropiadas para mitigarlos o compensarlos, correspondiendo también a los servicios públicos que posteriormente evalúan y califican el proyecto o actividad, certificar que se cumple con todos los requisitos ambientales aplicables, incluyendo las medidas de mitigación o restauración que procedan (inciso segundo del artículo 24 de la ley $\mathrm{N}^{\circ} 19.300$ ).

${ }^{8}$ Artículo 25 quinquies de la ley $\mathrm{N}^{\circ} 19.300$. 
refundir dos o más RCA no puede alterar el sentido y alcance de las RCA refundidas y sistematizadas, no hay duda que una acción como esta requiere hacer ajustes o cambios que se basan, previamente, en la interpretación de las normas, condiciones y medidas de una RCA.

Hacemos la prevención de que en razón de la dictación del Instructivo $\mathrm{N}^{\circ} 131.049$, de 1 de julio de 2013², del Servicio de Evaluación Ambiental, en virtud de lo dispuesto por la Contraloría General de la República (en adelante CGR), por medio del Dictamen $N^{\circ} 7620 / 20013$, las respuestas a las solicitudes de pertinencia deben ser expresadas "por escrito, con las formalidades pertinentes y debidamente individualizados con número y fecha”, a través de "una resolución”, cuestión que, eventualmente, gatilla que estas deban ser incorporadas al refundir o sistematizar una RCA, lo que, obviamente, implica un ejercicio de interpretación complejo.

\section{e) Reclamaciones}

Situación similar ocurre ante la presentación de recursos de reclamación ante RCA favorables o desfavorables que nieguen, rechacen o establezcan condiciones o exigencias a una Declaración (DIA) o un Estudio de Impacto Ambiental (EIA). De acuerdo al artículo 20 de la ley y dependiendo de la vía de ingreso del proyecto o actividad al SEIA, será el Director Ejecutivo o el Comité de Ministros, el órgano llamado a resolverlos. Así, dichos órganos también deberán interpretar si las condiciones o exigencias de una RCA, fueron o no debidamente motivadas y proporcionadas en relación a los fines buscados y al procedimiento de evaluación. En otras palabras, dichos órganos deben también realizar un ejercicio interpretativo a fin de resolver adecuadamente las reclamaciones interpuestas cuando ellas versan sobre una condición o exigencia impuesta a una RCA.

Otro tanto ocurre respecto de las resoluciones que realicen la revisión de una RCA, toda vez que de acuerdo a lo dispuesto en el inciso final del artículo 25 quinquies "el acto administrativo que realice la revisión podrá ser reclamado de conformidad a lo señalado en el artículo 20". En consecuencia, el Comité de Ministros debería conocer de dicha reclamación, en cuyo caso, también efectuará una labor de interpretación consistente en determinar si se cumplían o no los presupuestos legales y técnicos para realizar la revisión de una RCA.

\section{f) Fiscalización y sanción}

Por último, la propia SMA también interpreta las RCA y sus respectivas condiciones, normas y medidas al momento de verificar el cumplimiento de estas en distintas instancias, ya sea fijando los programas y subprogramas en función de las cuales posteriormente fiscalizará determinadas RCA y/o cuando ejerce su potestad sancionadora en caso que corresponda, incluyendo aquellos proponentes que deben ingresar al SEIA y aquellos titulares de

\footnotetext{
9 Disponible en: http://www.sea.gob.cl/archivos/instructivos/20130701-131049-consultas-pertinencias.pdf. Hacemos presente que en lo sucesivo este Instructivo quedará sin vigencia, sin perjuicio de lo cual, el que lo reemplaza (individualizado en la nota 5), contempla las mismas consideraciones respecto de las formas en que deben ser expedidas dichas respuestas.
} 
RCA que realicen modificaciones o ampliaciones (letra j y k) del artículo 3 de la LOC de SMA, ley $\mathrm{N}^{\circ}$ 20.417).

Lo mismo ocurre respecto de los procesos de sanción iniciados bajo el amparo de la ley $\mathrm{N}^{\circ} 20.473$, de 2010, que otorgó transitoriamente facultades fiscalizadoras y sancionadoras a la Comisión del artículo 86, antes de la entrada en vigencia de las facultades de la SMA, y que aún se ventilan ante esa sede, toda vez que en esos procesos también esos órganos deben "interpretar" el incumplimiento de una RCA, en atención a la fiscalización que hagan respecto de los proyectos los órganos de la Administración del Estado que participaron de la evaluación de la DIA o el EIA.

En todas las situaciones previamente descritas nos referimos a una potestad interpretativa respecto de actos administrativos (RCA) que tienen efectos particulares en cuanto a los destinatarios y específicos en relación a las obligaciones en ella contenidas ${ }^{10}$. En este sentido, la facultad de interpretación de la RCA no puede ser restringida al eventual control que al efecto puede hacer un determinado órgano, en este caso, el SEA, sino que también respecto de otras instancias, ni tampoco referirse a un alcance de carácter general y abstracto de la normativa ${ }^{11}$, sino que a los alcances particulares de un acto administrativo. Así, la interpretación de una RCA está sujeta a variadas circunstancias y distintos momentos de control, tanto administrativos como jurisdiccionales.

Administrativamente, conforme se dirá, el proceso de interpretación de una RCA no está exclusivamente asignado al SEA, como lo señala la ley $\mathrm{N}^{\circ} 19.300$ y conforme lo ha entendido la CGR en diversos dictámenes, particularmente en lo que dice relación con la dictación de pronunciamientos a consultas de pertinencias de ingreso, la facultad de revisión, el establecimiento del texto refundido, coordinado y sistematizado de una RCA, y de las demás normas, condiciones y medidas de una RCA. También corresponde a otros órganos administrativos, como la Superintendencia del Medio Ambiente, la cual, para efectos de ejercer sus facultades de fiscalización y sanción, necesariamente, debe interpretar la RCA con la finalidad de definir las actuaciones efectuadas por su infractor. Asimismo, por los servicios públicos con competencia ambiental que participan de la evaluación ambiental de una modificación de proyecto que cuenta con una RCA. Incluso, si se quiere, por parte de la CGR, en tanto está atribuida de potestades para revisar la juridicidad de una RCA, efectuando al respecto un proceso de interpretación de la misma, en relación a las normas, condiciones o medidas establecidas. Sin embargo, el control administrativo no se agota en esos órganos, toda vez que el Comité de Ministros o el Director Ejecutivo, según corresponda, pueden conocer e interpretar una RCA, en el marco de las reclamaciones que se pueden presentar al amparo de la ley ambiental.

Judicialmente, desde luego, todos esos actos administrativos, son susceptibles de ser impugnados ante los Tribunales de Justicia, a través de la acción de amparo general establecida en el artículo 20 de la CPR, o bien, a través de las correspondientes acciones estable-

\footnotetext{
10 Una situación que también debe ser resuelta, pero que escapa al objeto mismo de este trabajo, dice relación con la divisibilidad de una RCA. Si bien todavía es un asunto abierto en cuanto a si procede y si es oponible a la Administración Pública, lo concreto es que de proceder, no hay duda que también requiere de un ejercicio interpretativo por parte de la autoridad ambiental correspondiente.

11 Cordero Quinzacara (2010) p. 44.
} 
cidas en la ley $\mathrm{N}^{\circ}$ 20.600, que crea los Tribunales Ambientales. En este último caso, proceden las acciones establecidas en los números 5), 6) y 8) del artículo 17 de la referida ley, que, en síntesis, confieren el derecho de reclamar ante el Tribunal Ambiental, (i) cuando las reclamaciones interpuestas ante el Comité de Ministros o el Director Ejecutivo del SEA, agravien a los interesados en sus derechos, en conformidad con lo dispuesto en los artículos 20 y 25 quinquies de la ley No 19.300 (artículo $17 \mathrm{~N}^{\circ}$ 5), (ii) cuando las reclamaciones sean interpuestas por cualquier persona natural o jurídica en contra de la determinación del Comité de Ministros o Director Ejecutivo que resuelva el recurso administrativo, cuando sus observaciones no hubieren sido consideradas en el procedimiento de evaluación ambiental, en conformidad con lo dispuesto en los artículos 29 y 30 bis de la ley No 19.300, en relación con el artículo 20 de la misma ley (artículo $17 \mathrm{~N}^{\circ}$ 6), y (iii) cuando se interpongan reclamaciones en contra de la resolución que resuelva un procedimiento administrativo de invalidación de un acto administrativo de carácter ambiental (artículo 17 No 8).

Por eso, ante un escenario disperso en cuanto al objeto de la interpretación, los órganos intervinientes y los procedimientos aplicables al momento de interpretarse una RCA, se hace necesario contar con criterios que permitan, en estos u otros casos, fijar lineamientos que den estabilidad a esta importante potestad utilizando razonamientos comunes de solución.

\section{4. ÓRGANO COMPETENTE}

En un primer momento la CGR resolvió que correspondía a las Comisiones de Evaluación de cada región interpretar las $\mathrm{RCA}^{12}$. En tal sentido, dispuso que "es dable inferir que al órgano del Servicio de Evaluación Ambiental al cual corresponde interpretar la resolución de la ex Comisión Regional del Medio Ambiente de la Región del Biobío, que calificó como favorable ambientalmente el proyecto del centro que se trata, es la Comisión de Evaluación de esa región"13.

Con posterioridad, la CGR reiteró lo señalado previamente al expresar que son las Comisiones de Evaluación "a quienes compete evaluar los proyectos o actividades que sean susceptibles de originar impactos en una sola región”, correspondiendo "que sean esos órganos colegiados los que interpreten administrativamente las resoluciones de calificación ambiental que han sido dictadas respecto de aquéllos, tal como se manifestara en el referido dictamen $N^{\circ}$ 50.596, de 2012, de este Organismo Contralor" ${ }^{\prime 14}$.

De esta forma, la CGR dispuso que el órgano que califica proyectos es el llamado a interpretar una RCA sin hacer distinción alguna al respecto. El SEA entonces se desconcentraría en regiones a partir de Comisiones de Evaluación ${ }^{15}$ para el cumplimiento de sus potestades y no a través de sus Direcciones Regionales. Siguiendo lo dispuesto por la CGR en los dictamenes anteriores ( $\mathrm{N}^{\text {os }} 50.596 / 2012$ y $15.001 / 2013$ ), la atribución para interpretar

\footnotetext{
12 Dictamen $N^{\circ} 50.596 / 2012$.

13 Dictamen $N^{\circ} 50.596 / 2012$.

14 Dictamen $N^{\circ} 15.001 / 2013$.

15 Dictamen $\mathrm{N}^{\circ} 38.581 / 2013$.
} 
cualquier RCA (letra g) del artículo 81 de la ley) descansaría en un "órgano del Servicio de Evaluación Ambiental" que "forma parte de la estructura orgánica de dicha institución”16, denominado Comisión de Evaluación, en el caso de aquellos proyectos calificados en la región, y en el Director Ejecutivo, en aquellos que hayan tenido el carácter de interregional, pese a que la ley a ninguno de dichos órganos les entrega dicha atribución de manera expresa.

No obstante, la propia CGR también ha señalado recientemente que "tanto los directores regionales, como el Director Ejecutivo de la mencionada entidad se encuentran facultados para resolver la pertinencia de que un determinado proyecto sea sometido al sistema de evaluación de impacto ambiental" ${ }^{17}$. Como señalamos, el responder a una consulta de pertinencia constituye un ejercicio interpretativo toda vez que consiste, en base a los antecedentes proporcionados por el propio consultante, en dar cuenta de una opinión sobre la aplicabilidad de determinadas normas jurídicas a una situación concreta ${ }^{18}$, circunstancia que es recurrente cuando se trata de determinar si una RCA sufre o no un cambio de consideración. Este acto administrativo de juicio o de criterio resuelve, en base a los antecedentes acompañados, una situación jurídica concreta que, en base a una RCA - una de las dos modalidades posibles en materia de consulta de pertinencias- determina si esta sufrirá o no cambios de consideración que ameriten evaluarse ambientalmente.

Las contradicciones descritas merecen una aclaración. Si bien la CGR, en los primeros dictamenes sobre la materia, ha señalado que la interpretación corresponde a las Comisiones de Evaluación sin hacer distinción alguna, lo concreto es que hay un conjunto de situaciones concretas que requieren de una interpretación -como las consultas de pertinencias- en que otros órganos también participan. En función de lo anterior ¿quién tiene atribuciones para interpretar, en las diversas materias ya descritas y en sentido amplio, una RCA? Considerando que los cuatro dictámenes citados han sido dictados en un plazo de ocho meses, todo parecía indicar que había confusión en la CGR para efectos determinar quién es el órgano atribuido de la potestad necesaria para interpretar una RCA y bajo qué modalidad.

Respecto de la problemática anterior, huelga decirlo, CGR ha fijado una postura definitiva. El dictamen $N^{\circ}$ 62.223, de 27 de septiembre de 2013, ha indicado, expresamente, que "en el caso del Servicio de Evaluación Ambiental, la función establecida en el mencionado artículo 81, letra g), debe ser ejercida en el contexto de la estructura orgánica determinada por la señalada preceptiva y atendiendo al carácter de organismo descentralizado que le otorga el artículo 80 del texto legal en estudio, a través del jefe superior de esa entidad, que es su Director Ejecutivo".

Como se puede apreciar, CGR ha sido clara al señalar que el ejercicio de la facultad de interpretación, contenida en el artículo 81, letra g), de la ley, debe ser ejercida hoy por el Director Ejecutivo del SEA.

\footnotetext{
16 Dictamen $\mathrm{N}^{\circ} 15.001 / 2013$.

17 Dictamen $\mathrm{N}^{\circ} 7.620 / 2013$.

18 Véase el Instructivo señalado en la nota 6.
} 
Precisado aquello, reconocemos que se trata de una materia sujeta todavía a discusión, en cuanto a las modalidades descritas, órgano competente y procedimiento. Lo anterior, no obsta a ilustrar criterios orgánicos que permitan determinar quién tiene, en función de cada una de las modalidades, la facultad para interpretar una RCA, reconociendo que el principal problema se encuentra en dilucidar la potestad para interpretar los propios considerandos dudosos o confusos de una RCA, en razón de una petición concreta y específica. Creemos que el problema ha estado en no distinguir adecuadamente, cuestión que tampoco hace el legislador, las distintas instancias de interpretación que una RCA puede recibir. Dependiendo de cada una de ellas, el órgano llamado a interpretarlas será diferente.

Así, el profesor Luis Cordero ha planteado, en función de los Dictámenes citados, en particular a los Nos 50.596/2012 y 15.001/2013, que las consecuencias "de una decisión así, es que la certeza que buscaba la ley al establecer una potestad interpretativa de RCA (art. 81, letra g), ley $\mathrm{N}^{\circ}$ 19.300), se atomiza al reconocer a cada Comisión de Evaluación ese poder de decisión" ${ }^{19}$. Es decir, claramente a partir de la crítica del profesor Cordero y en razón de la confusión habida en su momento para determinar quién ostenta la potestad interpretativa descrita previamente, es que se hace indispensable, al menos en este y otros aspectos, determinar nítidamente qué órgano es el competente para determinar el sentido y alcance de una disposición de una RCA ante la petición o modalidad concreta que se requiera.

Lo anterior cobra sentido pues la interpretación de la RCA no es un asunto que concierna únicamente al SEA (ya sea a la Comisión de Evaluación, al Director Ejecutivo o a los Directores Regionales), sino también a otros órganos que también ejercen esta atribución permanentemente, pero en esferas distintas y bajo una modalidad recursiva o fiscalizadora, tales como el Comité de Ministros o el Director Ejecutivo del Servicio de Evaluación Ambiental, ambos según el artículo 20 de la ley, y la SMA.

\subsection{Consulta de PERTINENCiA}

Ante una consulta de pertinencia referida a si un proyecto o actividad debe o no ingresar al SEIA, hay acuerdo que es el Director Regional o Ejecutivo del SEA el que debe responder aquello ${ }^{20}$. Lo anterior constituye una respuesta que se da con anterioridad a que dicho proyecto se ejecute, por lo que dicha interpretación se limita a contrastar los hechos (actividades o proyectos a desarrollar descritos en una carta) con el derecho (si a dichos hechos le son o no aplicables las normas contenidas en la ley o en el reglamento del SEIA [RSEIA]), referentes a las tipologías en que la ejecución de un proyecto o el desarrollo de una actividad pudiesen ser subsumidas.

\footnotetext{
19 Cordero Vega (2013) p.1.
}

20 Conforme aparece del dictamen $N^{\circ} 7.620 / 2013$ de CGR, "tanto los directores regionales, como el Director Ejecutivo de la mencionada entidad se encuentran facultados para resolver la pertinencia de que un determinado proyecto sea sometido al sistema de evaluación de impacto ambiental...”. Lo anterior, sin perjuicio de que para un determinado proyecto ("Central Termoeléctrica Parinacota”) y respecto de modificaciones al mismo, la Excma. Corte Suprema resolvió mediante sentencias de 14 de enero de 2014, en los roles N $^{\text {os }} 7861$ y 9012, ambos de 2013, que "en el presente caso la respuesta a la consulta formulada por el titular del proyecto debía ser evacuada por la Comisión a que se refiere el artículo 86 de la Ley N 19.300”. 


\subsection{NORMAS, CONDICIONES Y MEDIDAS}

En relación a esta modalidad interpretativa, probablemente aquella en la que pensó el legislador al disponer el artículo 81 letra g) de la ley, hubo dudas, en un primer momento, en razón de los dictámenes recientemente dictados por la CGR, respecto de quién era el órgano competente. Resuelta esa situación, es dable manifestar que es el Director Ejecutivo del SEA el llamado a zanjar las dudas interpretativas que surjan de una RCA y no las Comisiones de Evaluación a través de la atribución implícita de potestades interpretativas que la CGR le había otorgado ${ }^{21}$.

En este sentido, cabe tener presente que la ley cita veinte veces a las Comisiones de Evaluación sin señalar en ninguna de ellas, expresamente, la potestad para interpretar una RCA. El artículo 81 letra g) le otorga dicha atribución al SEA mediante el cumplimiento de un procedimiento que la ley describe.

En esos términos, debe responderse una pregunta: ¿qué es el SEA? El propio artículo 80 de la ley lo define como un "servicio público funcionalmente descentralizado, con personalidad jurídica y patrimonio propio, y sometido a la supervigilancia del Presidente de la República a través del Ministerio del Medio Ambiente". Su finalidad, entre otras -incluida la de la interpretar las RCA-, consiste, principalmente, en la de administrar el SEIA. Es, en buenas cuentas, un servicio público de alcance nacional que satisface una necesidad pública concreta, de manera regular y continua -administrar el SEIA-, estando sometido a la supervigilancia del Presidente de la República a través del Ministerio del Medio Ambiente, cuyas políticas, planes y programas le corresponda aplicar ${ }^{22}$.

Se trata de un servicio público descentralizado que cuenta con patrimonio propio y personalidad jurídica, cuya relación con el Presidente de la República no está bajo el principio de jerarquía, sino que el de supervigilancia ${ }^{23}$. Asimismo, dicho servicio se desconcentra territorial y funcionalmente por medio de sus Direcciones Regionales (cuyas atribuciones exclusivas están radicadas en el artículo 15 bis y 18 bis de la ley), dependiendo, sus Directores Regionales, jerárquicamente, del Director Ejecutivo del SEA, quien tiene la representación judicial y extrajudicial del servicio ${ }^{24}$. Su actuar, como es natural, está sujeto al principio de juridicidad y por lo tanto, para que pueda efectuar sus actuaciones "sean de carácter favorable o desfavorable para los particulares, será necesario que dicho poder se encuentre regulado en la ley" 25 .

Para la CGR, tal como se señala en uno de los dictámenes citados, las Comisiones de Evaluación de cada región forman parte de la "estructura orgánica" del SEA. De igual forma se ha manifestado la Corte Suprema al señalar que "dentro del Servicio de Evaluación Ambiental se comprende precisamente a la Comisión de Evaluación Ambiental como el organismo encargado de calificar los proyectos, según consta del artículo 86 de la ley $\mathrm{N}^{\circ}$

\footnotetext{
21 Al respecto, véase Soto Kloss (1993) p. 687.

22 Artículo 28 de la LOC de Bases de la Administración del Estado, ley N ${ }^{\circ} 18.575$.

23 Para Soto Kloss, órganos como estos son "instituciones", es decir, "un conjunto abigarrado de servicios públicos personificados, que configuran parte de la llamada Administración Descentralizada...”, Soto Kloss (2013) p. 169.

24 En virtud de lo dispuesto en el artículo 83 letra h) de la ley.

25 Bermúdez (2011) p. 260.
} 
19.300 (modificada por la ley $N^{\circ}$ 20.417), norma que está inserta dentro del Título Final de la ley, párrafo sexto, que se refiere específicamente al Servicio de Evaluación Ambiental. Es decir, la Comisión es un órgano del Servicio de Evaluación Ambiental"26.

¿Era correcta esa interpretación? Creemos que no. La Comisión de Evaluación de cada una de las regiones del país no forma parte de la estructura orgánica del SEA, pues este se desconcentra, por ley, únicamente en sus Direcciones Regionales, constituyendo, las Comisiones de Evaluación, contempladas en el artículo 86 de la ley y cuyas atribuciones se encuentran dispersas en esta, un órgano de la Administración del Estado distinto, tal como lo es, también, el Comité de Ministros, cada uno con su respectiva organización y funcionamiento ${ }^{27}$.

No compartimos la opinión que un órgano, que lo integra el Intendente, como presidente, y un conjunto de otros miembros, como los Secretarios Regionales Ministeriales (SEREMIs), que corresponden a otros servicios (Ministerios) pueda ser parte del SEA. El hecho que el secretario de las Comisiones de Evaluación sea Director Regional del SEA no transforma a estas en parte de su estructura orgánica.

En efecto, siendo las Intendencias y Ministerios los órganos de donde emanan mayoritariamente los miembros de la Comisión de Evaluación, se concluye nítidamente que estos no solo no son parte del SEA sino que son órganos no personificados, centralizados y, por lo tanto, amparados bajo la personalidad jurídica del Fisco, siendo parte de la Administración del Estado bajo esa modalidad.

No debe olvidarse, además, que el Intendente es una persona de exclusiva confianza del Presidente de la República y que ejerce sus funciones con arreglo a las "órdenes e instrucciones del Presidente, de quien es su representante natural e inmediato en el territorio de su jurisdicción" (artículo 111 de la CPR). De igual forma, los "Ministros de Estado son los colaboradores directos e inmediatos del Presidente de la República en el gobierno y administración del Estado" (artículo 33 de la CPR), quienes por medio de sus SEREMIs integran dicho órgano. Quiérase o no, los miembros que componen la Comisión de Evaluación en cada región dependen directa y jerárquicamente, salvo el Director Regional del SEA, del Presidente de la República ${ }^{28}$.

Por lo tanto, más allá de consideraciones referidas al proceso de evaluación -el que también distingue entre evaluación y calificación, esta última instancia de cargo de la Comisión de Evaluación-, lo concreto es que orgánicamente se trata -pese a sus vinculaciones dentro del proceso de evaluación- de órganos distintos, no obstante lo dictaminado por la

\footnotetext{
26 Sentencia de la Corte Suprema, de 4 de abril de 2011 (Rol N 10.220-2012), considerando sexto, respecto del proyecto HidroAysén.

27 Cabe indicar que el referido Comité no forma parte de la estructura orgánica del SEA, en razón de (i) ser el órgano de la Administración del Estado dispuesto por la ley para efectos de revisar la juridicidad de ciertas resoluciones dictadas por el SEA, al conocer y resolver de las reclamaciones de los artículos 20, 25 quinquies y 29 de la ley; (ii) estar integrado por órganos centralizados (o no personificados), como los Ministros de Estado, cuestión que determinaría el absurdo de estimar que tales órganos se encuentran bajo el control jerárquico del Director Ejecutivo del SEA, que es el superior jerárquico de dicho servicio; y (iii) por encontrarse regulado jurídicamente en un párrafo distinto de la ley respecto del SEA.

28 La misma opinión, pero referida a las antiguas COREMA, era sustentada por BERMÚDEZ (2007) pp. 212213.
} 
CGR o la Corte Suprema, que intervienen en la evaluación y calificación de proyectos o actividades.

En consecuencia, lo expuesto nos permite entender que las Comisiones de Evaluación no forman parte del SEA y, por lo tanto, carecen de competencia para interpretar las RCA. Esa atribución, como bien señala el artículo 81 letra g), ha sido otorgada al Servicio de Evaluación Ambiental, el que por medio de su Director Ejecutivo -si es que no delega dicha atribución en sus Directores Regionales- es el encargado de llevarla a cabo, conforme ha resuelto CGR recientemente ( $\mathrm{N}^{\circ}$ 62.223/2013).

Por último, y al margen de los argumentos jurídicos expuestos, tampoco parece razonable para la adecuada funcionalidad del sistema, que existan distintas Comisiones de Evaluación interpretando este tipo de instrumentos, toda vez que existirán dieciséis órganos diferentes con competencia ambiental para llevar adelante la labor interpretativa, lo que podría atentar contra la adecuada certeza jurídica. Si a lo anterior se añade que dentro de las atribuciones del SEA está la de uniformar "criterios, requisitos, condiciones, antecedentes, certificados, trámites, exigencias técnicas y procedimientos de carácter ambiental que establezcan los ministerios y demás organismos del Estado competentes, mediante el establecimiento, entre otros, de guías de trámite" (artículo 81 letra d), resulta lógico que sea el Director Ejecutivo el órgano competente en materia de interpretación.

\subsection{REVISIÓN DE LA RCA}

El órgano competente para interpretar una RCA, en el marco del procedimiento de revisión de la misma, no es señalado expresamente por el legislador. Sin embargo, en nuestra opinión y en atención a una regla de radicación contenida en el artículo 9 inciso $2^{\circ}$ de la ley, en relación con lo dispuesto en los artículos 8 inciso final y 86 de la misma, y además en atención a la potestad de cualquier órgano de la Administración del Estado de poder volver sobre sus propios actos, a nivel regional, tal facultad será ejercida por la respectiva Comisión de Evaluación, mientras que tratándose de proyectos o actividades que cuenten con RCA y que puedan causar impactos ambientales en zonas situadas en distintas regiones, corresponderá al Director Ejecutivo.

Cuando se trate de proyectos que cuenten con una RCA dictada por una Comisión de Evaluación o por una Comisión Regional del Medio Ambiente, cuya modificación o modificaciones hayan sido calificadas por el Director Ejecutivo, por su carácter interregional, el ejercicio de esta facultad corresponderá al Director Ejecutivo, en su carácter de superior jerárquico.

\subsection{REFUNDIDO Y SISTEMATIZACIÓN}

El artículo 25 sexies establece que el ejercicio de esta potestad le corresponde al "Servicio", quien "de oficio o a petición del proponente, podrá establecer el texto refundido, coordinado y sistematizado de dicha resolución". Como es dable observar, la ley ha sido ambigua al momento de atribuir el ejercicio de esta potestad.

Sin embargo, creemos que, de acuerdo a la desconcentración territorial que establece el artículo 84 de la ley, a nivel regional dicha potestad debe ser ejercida por el Director Re- 
gional del SEA, en tanto que, tratándose de proyectos interregionales, le corresponderá su ejercicio al Director Ejecutivo del SEA.

En relación a lo anterior, cabe anotar que no solo por una razón orgánica es el Director Regional respectivo y no la Comisión de Evaluación el órgano competente para conocer de estas materias, sino que también por una cuestión de carácter sustantivo toda vez que el establecimiento del texto refundido de una RCA no obedece a consideraciones que impliquen, en los hechos, cuestiones de fondo o matrices. Es, en buenas cuentas, este acto, la consolidación de una información que ya está plasmada en otros documentos, pero que para efectos de orden y unidad, requiere su sistematización ${ }^{29}$.

En caso de que se trate de proyectos que cuenten con una RCA dictada por un órgano regional como la Comisión Regional del Medio Ambiente o Comisión de Evaluación, cuya modificación o modificaciones hayan sido calificadas por la Dirección Ejecutiva, el ejercicio de esta facultad corresponderá al Director Ejecutivo, en su carácter de Jefe del Superior del Servicio.

\subsection{ReClamaciones}

En términos generales, los recursos administrativos se definen como "mecanismos dispuestos a favor de los ciudadanos, de carácter impugnatorio, en los que se solicita por razones de legalidad o mérito, y ante la propia Administración, que un acto administrativo, previamente dictado, sea dejado sin efecto" ${ }^{30}$.

En ese contexto, mediante los recursos administrativos, la Administración tiene la oportunidad de revisar la juridicidad de sus propias actuaciones o la de sus órganos, a través de un instrumento de fiscalización interna ${ }^{31}$, generando, también, una interpretación de una RCA.

Ahora bien, la ley ha establecido un régimen especial respecto de los recursos administrativos que se pueden interponer tanto en contra de una RCA como del acto administrativo que realice la revisión de la RCA, respecto de los cuales los órganos llamados a conocerlos realizan un ejercicio interpretativo a fin de resolver adecuadamente las reclamaciones interpuestas.

Para efectos de establecer un orden, se trata de situaciones de diversa índole:

(i) Recursos de reclamación ante RCA favorables o desfavorables que nieguen, rechacen o establezcan condiciones o exigencias a una Declaración o a un Estudio; y

(ii) Recursos de reclamación que se interpongan en contra de un acto administrativo que realice la revisión de una RCA, conforme a lo dispuesto al artículo 25 quinquies.

\footnotetext{
29 En este sentido, la sentencia de la Ilustrísima Corte de Apelaciones de Temuco con fecha 13 de septiembre de 2013, recaída en los autos rol de ingreso $\mathrm{N}^{\circ}$ 2162-2013, considera que la resolución cuestionada "no es más que un compendio destinado a contener en un cuerpo armónico y ordenado de todas las disposiciones relativas al proyecto, destinado ello a facilitar su aplicación práctica y así otorgar certeza jurídica a su contenido” (considerando primero en relación al segundo).

30 Bermúdez (2011) p. 181.

31 Escuín Palor y Belando Garín (2011) p. 42.
} 
Así, respecto de aquellos recursos en contra de una RCA favorable o desfavorable que nieguen, rechacen o establezcan condiciones o exigencias a una DIA será competente el Director Ejecutivo del SEA, en tanto que respecto de un EIA, será competente el Comité de Ministros, conformado de acuerdo al artículo 20 de la ley, cuestión que también ocurre respecto de las reclamaciones que se interpongan en contra de una resolución que realice la revisión de una RCA, conforme a lo dispuesto en el artículo 25 quinquies.

\subsection{FISCALIZACIÓN Y SANCIÓN}

Conforme se indicó, la SMA de acuerdo a lo dispuesto en el artículo 3 letras j) y k) del artículo 2 de la ley $\mathrm{N}^{\circ} 20.417$, realiza un ejercicio de interpretación de la RCA y de sus respectivas condiciones, normas y medidas, cuando verifica el cumplimiento de estas en diversas instancias, ya sea cuando fija los programas y subprogramas en función de las cuales posteriormente fiscalizará determinadas RCA y/o cuando ejerce su potestad sancionadora en caso que corresponda, incluyendo aquellos proponentes que deben ingresar al SEIA y aquellos titulares de RCA que realicen modificaciones o ampliaciones.

Sin perjuicio de lo anterior, respecto de los procesos de sanción iniciados bajo el amparo de la ley $\mathrm{N}^{\circ} 20.473$, de 2010, que otorgó transitoriamente facultades fiscalizadoras y sancionadoras a la Comisión del artículo 86, es dable indicar que sería la referida Comisión o el Director Ejecutivo en su caso, los órganos competentes para sancionar el incumplimiento a una RCA y en consecuencia interpretar su normas, condiciones y/o medidas, en caso que corresponda.

\section{PROCEDIMIENTO}

Junto con definir el órgano con competencias para interpretar una RCA, es importante señalar la forma en que se ejerce dicha potestad en las distintas modalidades previamente descritas. En esos términos, conviene, entonces, detenerse igualmente en el procedimiento aplicable para interpretar una RCA.

\subsection{Consulta de PeRTinencia}

En razón de que no hay ley que resuelva este tipo de solicitudes, debe estarse al procedimiento general establecido por la ley $\mathrm{N}^{\circ} 19.880$ en sus artículos 18 y siguientes, considerando para dichos efectos, las etapas propias del procedimiento: iniciación, instrucción y finalización ${ }^{32}$.

\subsection{NORMAS, CONDICIONES Y MEDIDAS}

En el caso de la interpretación de las normas, condiciones y medidas contenidas en una RCA cabe indicar que el artículo 81 letra g) de la ley $\mathrm{N}^{\circ} 19.300$ no establece un procedimiento preciso para efectos de ejercer dicha potestad. Señala, únicamente, que el SEA deberá solicitar informe a los "organismos con competencia en la materia específica que participaron de la evaluación, del Ministerio y la Superintendencia del Medio Ambiente,

32 Lo anterior, sin perjuicio de seguir lo dispuesto en el Instructivo señalado en la nota 6. 
según corresponda", los cuales, si tratan aspectos normados sometidos a las facultades de interpretación administrativa del organismo sectorial respectivo, "tendrá el carácter de vinculante" en relación a esa materia.

$\mathrm{Al}$ respecto, se debe tener presente que la norma en comento establece la necesidad de contar, en forma previa y según corresponda, con los dictámenes o informes de los organismos con competencia en la materia específica que participaron de la evaluación, del Ministerio y la SMA.

De acuerdo a los siguientes aspectos, lo anterior es evidente, desde que:

(i) Los órganos que participaron de la evaluación se pueden pronunciar respecto de los aspectos técnicos y jurídicos contenidos en una norma de carácter sectorial de su competencia, tal como lo realiza la Superintendencia de Electricidad y Combustible (en adelante SEC), en virtud de lo dispuesto en el artículo $3 \mathrm{~N}^{\circ} 34$ de la ley $\mathrm{N}^{\circ}$ 18.410, que la crea ${ }^{33}$;

(ii) El Ministerio del Medio Ambiente, en las materias que son de su competencia, tales como aquellas contenidas en la letra o) del artículo 70 de la ley $\mathrm{N}^{\circ} 19.300$, interpreta administrativamente "las normas de calidad ambiental y de emisión, los planes de prevención y, o de descontaminación” y uniforma "los criterios de aplicación" y aclara "el sentido y alcance de las normas de calidad ambiental y de emisión, cuando observe discrepancias o errores de interpretación"; y

(iii) La SMA, en la medida que se aboque a "fiscalizar el permanente cumplimiento de las normas, condiciones y medidas establecidas en la Resolución”, pues en tal caso, la fiscalización de esas autorizaciones de funcionamiento importan el ejercicio de potestades de interpretación respecto de la actuación del titular de esa RCA, sobre la base de "inspecciones, controles, mediciones y análisis que se realicen, de conformidad a lo establecido en esta ley".

Ahora bien, la norma en comento incurre en un error. En efecto, el artículo 81 letra g) de la ley refiere que el informe solicitado tendrá el carácter de vinculante "para el Ministerio en relación a esa materia", cuando "contuviese aspectos normados sometidos a las facultades de interpretación administrativa del organismo sectorial respectivo". Como es dable observar, el error en el que se incurre consiste en la referencia efectuada respecto del órgano competente para interpretar una RCA, desde que el Ministerio (del Medio Ambiente) no ha sido atribuido de potestades de interpretación administrativa de estas autorizaciones ambientales, sino que respecto de otras materias, como las precedentemente indicadas en el artículo 70 letra o) de la ley $\mathrm{N}^{\circ} 19.300$, por lo que la referencia debe entenderse hecha al Servicio de Evaluación Ambiental.

Algo distinto, pero que es necesario dilucidar, es la referencia que la ley ha realizado respecto del carácter vinculante del informe del órgano respectivo. Para efectos de

\footnotetext{
33 Dice esa norma que será de competencia de la SEC, "Aplicar e interpretar administrativamente las disposiciones legales y reglamentarias cuyo cumplimiento le corresponde vigilar, e impartir instrucciones de carácter general a las empresas y entidades sujetas a su fiscalización”.
} 
interpretar una RCA, se refiere únicamente a aquellos aspectos normados: ¿qué ha querido señalar el legislador con aquello? La verdad de las cosas, es que la ley no ha explicado con la claridad necesaria este asunto, sin perjuicio que ha entregado algunas luces. El concepto "aspectos normados" ha sido nombrado por la ley en dos disposiciones: (i) en el artículo $9^{\circ}$ bis inciso primero de la ley $\mathrm{N}^{\circ} 19.300$, a propósito del carácter vinculante del Informe Consolidado de Evaluación (en adelante ICE), solo en "relación con los aspectos normados en la legislación ambiental vigente"; y (ii) en el caso del artículo 81 letra g) inciso segundo en análisis.

Resulta que en el primer caso, el ICE es vinculante para el órgano calificador respectivo, solo en lo que dice relación con los aspectos normados en la legislación ambiental vigente, entendiendo por aquello la normativa ambiental aplicable al proyecto ${ }^{34}$. Es decir, si el ICE establece que el proyecto o actividad cumple con aquella normativa, la Comisión de Evaluación o el Director Ejecutivo, según corresponda, no tiene margen alguno de discrecionalidad y debe estimarla por cumplida. En esos términos, nos referimos, por ejemplo, a lo dispuesto en un instrumento de planificación territorial (en adelante IPT), que fija el uso de un territorio dado, tal como sería su uso industrial, residencial o mixto. En estas materias, no cabe más que aplicar de manera concreta y directa la norma, la que precisa, finalmente, lo que puede o no realizarse en un lugar.

En el mismo sentido, los aspectos normados vinculantes para el SEA, en el ejercicio de la potestad de interpretación administrativa, se refieren a aquellas materias técnicas o jurídicas contenidas en el ordenamiento jurídico sectorial respectivo, pero no aquellas que dicen relación con cuestiones propiamente ambientales, por ejemplo, sobre aspectos técnicos que dicen relación con la evaluación de la significancia de los impactos del proyecto, encaminados a determinar si aquellos causan alguno de los efectos, características o circunstancias del artículo 11 de la ley $\mathrm{N}^{\circ}$ 19.300. Así, en contraste con la regulación específica que tiene un IPT, no hay duda que una medida de mitigación o compensación no es, en sí misma, un aspecto normado y que queda, finalmente, entregado, en buena medida, a la potestad discrecional de quien la requiera.

Es en este terreno que el SEA detenta un espacio de discrecionalidad al ejercer la potestad de interpretación administrativa, solo siendo vinculante el informe del organismo del Estado con competencia ambiental respectivo, en aquellos aspectos jurídicos y técnicos normados en la ley del ramo.

Ahora bien, cabe indicar que la ley $\mathrm{N}^{\circ} 19.300$ no ha regulado mayormente el procedimiento administrativo de interpretación de una RCA, salvo en lo que dice relación con el órgano competente y la solicitud de informes y su carácter vinculante. Así, no ha regulado aspectos tan importantes como la iniciación, instrucción y decisión del proceso, que son las etapas propias de todo procedimiento. En ese escenario, y atendido al vacío normativo contenido en la ley $\mathrm{N}^{\circ} 19.300$, debe aplicarse supletoriamente el procedimiento ordinario establecido en la ley $\mathrm{N}^{\circ} 19.880$, de acuerdo a lo establecido en su artículo $1^{\circ}$ inciso primero, considerando para dichos efectos "instituciones comunes a la totalidad de

34 A mayor abundamiento, véase GuZMán (2010) pp. 156-158. 
las actuaciones derivadas del desarrollo de la actividad formalizada de cualesquiera" administración pública ${ }^{35}$.

(i) Iniciativa: La ley no indica mayormente este aspecto. En nuestra opinión, el procedimiento podría ser iniciado: (a) de oficio por propia iniciativa del SEA, o como consecuencia de una orden superior, a petición de otros órganos, como la SMA, o por denuncia de cualquier persona directamente afectada, de acuerdo con los criterios establecidos en el artículo 21 de la ley $\mathrm{N}^{\circ} 19.880^{36}$; o (b), a través de una petición efectuada por el titular de la RCA.

(ii) Instrucción: Los actos de instrucción son aquellos necesarios para la determinación, conocimiento y comprobación de la conveniencia, oportunidad o mérito de interpretar una RCA.

Para instruir el procedimiento de interpretación, en el caso que se trate de una solicitud efectuada por el titular de la RCA o de una persona directamente afectada, se requiere contar con una solicitud que cumpla los requisitos establecidos en el artículo 30 de la ley $N^{\circ} 19.880$, acompañando especialmente los documentos o antecedentes, contenidos en informes, análisis o estudios, que le permitan a la autoridad ambiental conocer el asunto, pudiendo esta última, si lo estima, requerir antecedentes adicionales de acuerdo al artículo 31 de la ley $\mathrm{N}^{\circ} 19.880$.

En cuanto al plazo que debe observarse en el procedimiento de interpretación de la RCA, debe estarse al plazo máximo contenido en el artículo 27, el cual "salvo caso fortuito o fuerza mayor, no podrá exceder de 6 meses".

Los hechos relevantes para la interpretación, pueden "acreditarse por cualquier medio de prueba admisible en derecho, apreciándose en conciencia”, de acuerdo a lo preceptuado por el artículo 35 de la ley $\mathrm{N}^{\circ} 19.880$.

Por otra parte, cabe indicar que la solicitud de informes, regulada en los artículos 37 y 38 de la ley, no es aplicable en este procedimiento, toda vez que la ley $\mathrm{N}^{\circ} 19.300$, precisa el órgano y el carácter vinculante de los mismos, haciendo excepción a lo establecido en el inciso primero del artículo 38.

Sin embargo, y no obstante no ser aplicable, en términos generales, lo contenido en dichos artículos, cabe anotar que la ley $\mathrm{N}^{0} 19.300$ no se refiere a la circunstancia de que requerido el informe, este no hubiese sido evacuado por el organismo sectoriales respectivo dentro de un plazo prudente, caso en el cual, conforme lo expresa el artículo 38 inciso segundo, "se podrán proseguir las actuaciones".

35 Parejo (2012) p. 330.

36 Sin perjuicio de lo dicho, hacemos presente que la determinación de las personas que están legitimadas para solicitar la interpretación de una RCA a la autoridad ambiental es un tema no resuelto aún. En este sentido, y como hemos indicado, creemos que la legitimidad para solicitar el inicio de un procedimiento interpretativo en sede administrativa, debe entenderse en términos amplios, reconociendo incluso, como lo hace Bordalí, la posibilidad para que la acción individual permita "realizar no solamente la satisfacción del derecho o interés del sujeto que actúa, sino también aquella del interés colectivo”, Bordalí (2004) pp. 263-264. 
Finalmente, en nuestra opinión, estimamos pertinente la aplicación del artículo 39 de la ley, que se refiere al periodo de información pública en los procedimientos administrativos, cuando "la naturaleza de este lo requiera", particularmente cuando se refiera a aquellas solicitudes de interpretación de una RCA de un EIA.

(iii) Decisión: Respecto de la conclusión del procedimiento, cabe indicar que la forma natural de término del procedimiento es mediante la dictación de una resolución sobre la interpretación de la RCA, sin perjuicio de las demás formas de término de procedimiento, contenidas en el artículo 40 de la ley $\mathrm{N}^{\circ} 19.880$.

Dicha resolución, conforme lo dispone el artículo 45 y siguientes de la ley $\mathrm{N}^{\circ}$ 19.880, deberá ser notificada al interesado conteniendo su texto íntegro.

Si el acto administrativo puede interesar a un número indeterminado de personas o bien contenga normas de general aplicación, será necesario publicarlo en el Diario Oficial, conforme lo señala el artículo 48 letras a) y b) de la ley $\mathrm{N}^{\circ} 19.880^{37}$.

Por último, es necesario indicar que tratándose de un acto administrativo, proceden a su respecto los recursos administrativos ordinarios establecidos en la ley de procedimiento administrativo, esto es, los recursos de reposición y jerárquico ${ }^{38}$ de acuerdo a lo establecido en los artículos 59 y 60 de la ley $\mathrm{N}^{\circ} 19.880$, sin perjuicio de las demás formas de revisión de los actos administrativos que señala la misma ley, tales como la invalidación, la revocación, la aclaración o el recurso extraordinario de revisión.

\subsection{REVISIÓN DE LA RCA}

De igual forma, cuando se interpreta una RCA a partir de su revisión, el artículo 25 quinquies señala un procedimiento.

El artículo 25 quinquies dispone en su inciso segundo lo siguiente:

"Con tal finalidad se deberá instruir un procedimiento administrativo, que se inicie con la notificación al titular de la concurrencia de los requisitos y considere la audiencia del interesado, la solicitud de informe a los organismos sectoriales que participaron de la evaluación y la información pública del proceso, de conformidad a lo señalado en la ley No 19.880 ”.

\footnotetext{
37 Véase, al respecto, con suma detención, el considerando undécimo de la sentencia de 2 de mayo de 2013 de la Excma. Corte Suprema (Rol No 3918-2012), respecto del proyecto Hotel Punta Piqueros, que dispuso la obligación de publicar los actos administrativos cuando "contengan normas de general aplicación o que miren al interés general", como ocurre en el caso del otorgamiento de un permiso de edificación por la Dirección de Obras respecto de un proyecto hotelero, cuyas características y magnitudes pueden afectar el borde costero de Concón, la que constituye una "zona de innegables atributos naturales y paisajísticos".

38 El recurso jerárquico es procedente, en la medida que, de forma previa, el Director Ejecutivo del SEA haya delegado expresamente la potestad para interpretar administrativamente una RCA, en alguno de sus directores regionales, en quienes se desconcentra territorialmente de acuerdo a lo establecido en el artículo 84 de la ley.
} 
En síntesis, la norma exige la instrucción de un procedimiento administrativo que contenga los siguientes actos trámites:

(i) La notificación al titular, respecto de la concurrencia de los requisitos para la procedencia de la revisión de la RCA;

(ii) La audiencia del interesado. En este caso, y al igual que lo exigido en el artículo 53 de la ley $\mathrm{N}^{\circ} 19.880$, la autoridad ambiental deberá emplazar al respectivo interesado para que haga valer sus derechos dentro del plazo que esta determine. Si bien la ley No 19.880 no resuelve el punto, un plazo razonable para que el interesado se pronuncie respecto de la procedencia de la revisión, es de 10 días hábiles administrativos, de acuerdo a lo establecido en el artículo 24 de la misma ley;

(iii) La solicitud de informe a los organismos sectoriales que participaron de la evaluación, los cuales en virtud de la remisión expresa a la ley $N^{\circ} 19.880$ serán facultativos y no vinculantes para el SEA; y

(iv) La información pública del proceso, de conformidad con lo dispuesto en el artículo 39 de la ley $\mathrm{N}^{\circ} 19.880$.

Dicho procedimiento, al igual que para el caso de las consultas de pertinencia de ingreso, será tramitado conforme a las reglas generales fijadas en la ley No 19.880, en particular, en su Capítulo II, en los plazos definidos por los artículos 25, 26 y 27, no pudiendo exceder de seis meses.

En iguales términos, tampoco puede descartarse que esta atribución pueda ser ejercida, al menos procedimentalmente, siguiendo la fórmula propia de una EIA pero con matices, es decir, solicitando a los servicios públicos su parecer y permitiendo un proceso de consulta a los interesados, tal como de hecho ha ocurrido en ciertos procesos ${ }^{39}$.

En cuanto a su impugnación, la norma en comento dispone que el acto administrativo que realice la revisión podrá ser reclamado de conformidad a lo señalado en el artículo 20 de la ley No 19.300 .

Lo anterior, quiere decir que procede la interposición de un recurso de reclamación ante el Comité de Ministros. Un aspecto relevante que se podría ventilar en esta sede está dado por la procedencia (adicional) de impugnar el acto administrativo que realice la revisión a través de los recursos administrativos ordinarios contenidos en la ley $\mathrm{N}^{\circ} 19.880$. Así, por ejemplo, ¿procede la interposición de un recurso de reposición ante el mismo órgano que lo dictó, o bien un recurso jerárquico? En nuestra opinión, tales recursos no son procedentes, en atención a que la propia ley $\mathrm{N}^{\circ} 19.300$ resolvió el asunto, no existiendo vacío normativo alguno que llenar mediante la aplicación supletoria de la ley de procedimiento administrativo.

Ahora bien, respecto de una eventual impugnación de la resolución que da inicio al procedimiento de revisión, entendemos que solo es impugnable la resolución que realice

\footnotetext{
39 En efecto, respecto de la revisión de la RCA del proyecto Convento Viejo, se ha procedido en conformidad a esas reglas. Disponible en: http://www.sea.gob.cl/contenido/revision-de-la-rca-del-proyecto$\%$ E2\%80\%9Cembalse-convento-viejo-etapa-ii $\%$ E2\%80\%9D-ubicado-en-la-region-del
} 
la revisión, esto es, aquella resolución que ponga fin al procedimiento de revisión. Lo anterior, toda vez que la norma en comento lo señala en su inciso final y, por otra parte, las resoluciones de mero trámite, en principio, no tienen la entidad suficiente para generar perjuicio a los derechos de los interesados, de conformidad con lo dispuesto en el artículo 15 inciso segundo de la ley $\mathrm{N}^{\circ} 19.880^{40}$.

\subsection{REFUNDIDO Y SISTEMATIZACIÓN}

La solicitud de establecimiento del texto refundido, coordinado y sistematizado de una RCA que ha sido modificada por una o más resoluciones, debe ser presentada ante la autoridad respectiva, esto es, ante el Director Regional o Ejecutivo, según corresponda, pudiendo el titular presentar una propuesta del texto.

El procedimiento que se debe observar es aquel contenido en el Capítulo II de la ley $\mathrm{N}^{\circ} 19.880$, en los plazos definidos por los artículos 25, 26 y 27, no pudiendo exceder de seis meses.

El acto administrativo que resuelva sobre la petición de establecer el texto refundido de una RCA, estará contenido en una resolución, la cual se pronunciará respecto de las resoluciones consideradas y contendrá los cambios de forma que sean indispensables, sin alterar, en caso alguno, su verdadero sentido y alcance. Es dable indicar, además, que la referida resolución deberá ser notificada al titular conforme al artículo 46 de la ley de procedimiento administrativo e informada a los órganos que participaron de la evaluación ambiental de los proyectos y a la SMA, para efectos de su seguimiento y fiscalización.

Cabe, por último, indicar que la ley no menciona los recursos administrativos que proceden en contra de la misma. Al respecto, consideramos que en atención al vacío normativo de la ley, proceden los recursos administrativos ordinarios establecidos en la ley $\mathrm{N}^{\circ}$ 19.880, sin perjuicio de las demás formas de revisión y recursos o acciones jurisdiccionales a que haya lugar.

\subsection{ReCLAMACIONES}

Como es sabido, la ley $\mathrm{N}^{\circ} 19.300$ ha atribuido al Comité de Ministros, regulado en el artículo 20, potestades para efectos de revisar la juridicidad de determinados actos administrativos que emanan del SEA, entre los cuales se cuenta:

(i) Conocer y resolver los recursos de reclamación que presente el responsable del respectivo proyecto en contra de las resoluciones que rechacen o establezcan condiciones o exigencias a un EIA, en conformidad al artículo 20 de la ley $\mathrm{N}^{\circ} 19.300$;

(ii) Conocer y resolver las reclamaciones en contra de las resoluciones que realicen la revisión de una RCA, de acuerdo al artículo 25 quinquies de la ley $\mathrm{N}^{\circ} 19.300$; y

\footnotetext{
40 En este sentido, el considerando noveno de la sentencia de 26 de marzo de 2013, de la Excelentísima Corte Suprema, Rol Nº - 2013, respecto del proyecto "Estacionamientos Subterráneos y Superficie, Plaza de Armas de San Felipe", es ilustrativo en este aspecto.
} 
(iii) Conocer y resolver recursos de reclamación presentados por las personas que hubieren formulado observaciones al EIA y que estimaren que sus observaciones no han sido consideradas, en conformidad al artículo 29 de la ley $\mathrm{N}^{\circ} 19.300$.

El procedimiento que debe observarse cuando se interprete una RCA, ya sea tratándose de los recursos que el titular o la ciudadanía presenten o de la resolución que realice la revisión conforme al artículo 25 quinquies, es el mismo, toda vez que en todos los casos debe observarse lo dispuesto en el artículo 20.

En efecto, para lo anterior, el Comité de Ministros, presentadas las reclamaciones, podrá "solicitar a terceros, de acreditada calificación técnica en las materias de que se trate, un informe independiente con el objeto de ilustrar adecuadamente la decisión".

La misma norma, reconduce a la potestad reglamentaria la selección de "dicho comité y las condiciones a las que deberá ajustarse la solicitud del informe”. Asimismo, dispone en el caso de los EIA, que se "deberá solicitar siempre informe a los organismos sectoriales que participaron de la evaluación ambiental”, no estableciendo el carácter de dichos informes, por lo que en tal caso, deberá estarse a lo establecido en el artículo 38 inciso segundo de la ley $\mathrm{N}^{\circ} 19.880$, en carácter de supletorio, no siendo vinculantes para el Comité los referidos informes.

Respecto de la competencia del Comité de Ministros para la resolución de tales reclamaciones cabe anotar que esta es amplia ${ }^{41}$, toda vez que los principios generales en materia de impugnación de actos administrativos, contenidos en los artículos 15, 56 y 59, todos de la ley $\mathrm{N}^{\circ} 19.880$, refieren que el órgano que conoce de la reclamación puede, al acoger un recurso administrativo, "dictar por sí misma el acto de reemplazo", u ordenar "que se corrijan por la Administración o por el interesado, los vicios que advierta en el procedimiento, fijando plazos para tal efecto", o "modificar, reemplazar o dejar sin efecto el acto impugnado".

En este sentido, cabe anotar que atendido que la ley $\mathrm{N}^{\circ} 19.300$ regula escuetamente el procedimiento de reclamación, es dable aplicar, en carácter de supletorio, lo dispuesto en la ley $\mathrm{N}^{\circ} 19.880$, en aquellas materias que sean conciliables.

Finalmente, es oportuno indicar que las resoluciones dictadas por el Comité de Ministros deben ser fundadas, vale decir, motivadas ${ }^{42}$, debiendo expresar las razones de hecho y de derecho por las cuales se arribó a esa decisión, y son impugnables a través de la interposición de una reclamación judicial, la cual deberá interponerse dentro del plazo de treinta días contados desde su notificación, "ante el Tribunal Ambiental, de conformidad con lo dispuesto en los artículos 60 y siguientes de esta ley”, conforme lo dispone el artículo 20, plazo que de acuerdo a lo dispuesto en el artículo 88 es de "días hábiles, entendiéndose que son inhábiles los días sábado, domingo y festivos".

\footnotetext{
41 Pero debiendo ser congruente, como lo recuerda SÁnchez (2012), respecto de las peticiones formuladas por el recurrente, admitiendo la posibilidad de decidir "cuestiones no alegadas, pero siempre que no se trate de cuestiones nuevas sino que se deduzcan del expediente", p. 841.

42 Aróstica (1986) p. 500.
} 


\subsection{FISCALIZACIÓN Y SANCIÓN}

La interpretación de una RCA, por parte de la Superintendencia del Medio Ambiente, se puede dar en dos ámbitos de actuación: en el ejercicio de potestades de fiscalización y de sanción.

Respecto de lo primero, la SMA tiene atribuida potestades en virtud de lo dispuesto en el artículo $3^{\circ}$ letra a) de su ley orgánica, para "fiscalizar el permanente cumplimiento de las normas, condiciones y medidas establecidas en las Resoluciones de Calificación Ambiental, sobre la base de inspecciones, controles, mediciones y análisis que se realicen, de conformidad a lo establecido en esta ley".

Dicha fiscalización podrá ser realizada por la propia SMA o por los órganos sectoriales, cuando corresponda. En ese ámbito, la Superintendencia podrá "contratar las labores de inspección, verificación, mediciones y análisis del cumplimiento de las normas, condiciones y medidas de las Resoluciones de Calificación Ambiental,... cuando correspondan, a terceros idóneos debidamente certificados".

La fiscalización de la RCA importa la interpretación de la misma, considerando para dichos efectos las "inspecciones, controles, mediciones y análisis que se realicen, de conformidad a lo establecido en esta ley”. Para estos efectos, el artículo 22 de su ley orgánica establece que la Superintendencia "realizará la ejecución de las inspecciones, mediciones y análisis que se requieran para el cumplimiento de los programas y subprogramas de fiscalización", pudiendo asimismo impartir "directrices a los mencionados organismos sectoriales, informando, las acciones de fiscalización que éstos asumirán, los plazos y oportunidades para su realización y las demás condiciones pertinentes".

Sin perjuicio de lo anterior, cabe indicar que el artículo $3^{\circ}$ letra p) de la ley de la SMA establece un mecanismo que permite evaluar y certificar la normativa ambiental aplicable y el cumplimiento de las condiciones de una autorización de funcionamiento ambiental por parte de entidades certificadoras, las que pueden otorgar un certificado respecto de dichas materias, que constituye "prueba suficiente de cumplimiento de la normativa específica de que se trata y de los hechos vinculados a ella que fueron evaluados por los certificadores, por lo que no podrá iniciarse procedimiento sancionatorio por los hechos objeto de la certificación".

En segundo lugar, la interpretación administrativa de una RCA también se realiza en el marco de un procedimiento administrativo sancionatorio ${ }^{43}$ iniciado por la SMA de acuerdo al artículo 47 por las formas allí indicadas, esto es, de oficio, a petición de un órgano sectorial o por denuncia.

Sobre esto último, cabe indicar que la denuncia efectuada originará un procedimiento sancionatorio "si a juicio de la Superintendencia está revestida de seriedad y tiene mérito suficiente", caso en el cual, desde luego, la SMA debe determinar el sentido, alcance, serie-

43 Toda vez que la potestad sancionatoria, según Nieto, importa el ejercicio de "tres facultades básicas -la de establecimiento normativo, la de imposición y la de ejecución- que concurren conjunta o separadamente en cada Administración titular de la potestad, según los casos, y con un contenido o alcance muy variable”, cuestión que desde luego requiere un proceso de interpretación, particularmente, respecto de la segunda facultad, esto es, la "determinación de las infracciones y de los infractores concretos así como en la imposición de sanciones”, NieTo (2012) p. 99. 
dad, gravedad, oportunidad y mérito de iniciar un procedimiento de sanción ${ }^{44}$. En otras palabras, que sea fruto de un procedimiento valorativo, de interpretación. Sobre esto, no debe olvidarse, a este respecto, que la SMA al momento de sancionar un proyecto no solo considera el alcance y sentido de determinadas leyes y reglamentos, sino que fundamentalmente tiene como referencia la propia RCA, que fija el ámbito como acto administrativo de carácter normativo respecto del incumplimiento de determinas obligaciones, medidas o condiciones, constituyendo un "micro ordenamiento jurídico aplicable a la construcción, ejecución y cierre de un proyecto o actividad" 45 .

En caso que la denuncia adolezca de tales vicios, vale decir, que no esté revestida de la seriedad y mérito suficiente, el artículo 47 inciso final establece que "se podrá disponer la realización de acciones de fiscalización sobre el presunto infractor y si ni siquiera existiere mérito para ello, se dispondrá el archivo de la misma por resolución fundada, notificando de ello al interesado".

La determinación de la procedencia de medidas provisionales, como las que describe el artículo 48 de la ley de la SMA, también exige un proceso de interpretación de una RCA, cuando se estime pertinente la adopción de tales medidas respecto de un proyecto en ejecución. Particularmente lo anterior, dice relación con la necesidad de evitar daños inminentes al medio ambiente o a la salud de las personas. Esa determinación, esto es, aquella destinada a evitar el daño sobre tales bienes jurídicos, importa una interpretación sobre cuál es la medida más conveniente y oportuna para el caso concreto.

Una vez instruido el proceso de sanción, con la formulación precisa de los cargos y la notificación al presunto infractor, este deberá efectuar los descargos dentro del plazo de 15 días. Cabe indicar que la formulación de cargos exige un proceso de verificación e interpretación del incumplimiento cometido, debiendo contener dicho documento "una descripción clara y precisa de los hechos que se estimen constitutivos de infracción y la fecha de su verificación, la norma, medidas o condiciones eventualmente infringidas y la disposición

\footnotetext{
44 En contra de tales determinaciones, García, para quien las Superintendencias se han "convertido en poderosas agencias estatales capaces de interpretar autónomamente normas jurídicas, imponer dicha interpretación a los particulares y sancionar su incumplimiento”, GARcía (2009) p. 331. En el mismo sentido Díaz de Valdés, quien estima que uno de los vicios más graves respecto de las potestades atribuidas a las Superintendencias, está dado por el hecho que "las competencias tienden a ser amplias, redactadas en términos muy genéricos, en ocasiones vagos, otorgando un margen tan ancho de alternativas de interpretación, que de alguna manera vacían de contenido a la garantía de la consagración legal”, margen de interpretación que en estricto rigor, estima, solo "obliga a la propia superintendencia que la realiza y al resto de la Administración del Estado, con la posible excepción de la CGR", y respecto de la cual los particulares mantienen la oportunidad de impugnarla ante los tribunales, DíAZ DE VALdÉs (2010) p. 252 y p. 259. En una posición intermedia, Camacho, para quien es "problemático definir que tipo de potestad normativa es la que se atribuye a estos organismos", sin perjuicio de considerar que estos órganos "son la expresión de un importante cambio orgánico y funcional de la Administración del Estado y del nuevo rol que este asume como consecuencia del proceso liberalizador de la economía”, САмаCHO (2005) p. 430 y p. 423. En un sentido contrario, Bermúdez, quien es partidario del modelo de organización administrativa seguido por la ley $\mathrm{N}^{\circ} 20.417$, para efectos de la protección del medio ambiental, a través de una Superintendencia, la cual "forma parte de los organismos para el control de las actividades económicas", atribuida de un "poder fuerte que efectivamente cumpla un rol de prevención general", BERMÚdeZ (2013), p. 425, p. 431 y p. 445.

45 Cordero Vega (2013) p. 1.
} 
que establece la infracción, y la sanción asignada”, conforme lo exige el artículo 49 de la ley de la SMA.

También un proceso lógico de interpretación es exigido respecto de las eventuales medidas o diligencias probatorias solicitadas por el presunto infractor en sus descargos, toda vez que la autoridad fiscalizadora las podrá otorgar en la medida que sean pertinentes y conducentes, en cuyo caso, si no proceden, deberá rechazarlas por resolución motivada.

Lo anterior también se verifica respecto de la apreciación de la prueba aportada, ya que el artículo 51 dispone que deberá efectuarse "conforme a las reglas de la sana crítica".

Finalmente, cabe indicar que "cumplidos los trámites señalados en los artículos anteriores, el fiscal instructor del procedimiento emitirá, dentro de cinco días, un dictamen en el cual propondrá la absolución o sanción que a su juicio corresponda aplicar", vale decir, el fiscal instructor, de acuerdo a los antecedentes proporcionados y al análisis de la prueba aportada conforme a la sana crítica, propondrá la absolución o sanción respecto del incumplimiento en el que se ha incurrido por el titular de una RCA, todo en base a un proceso interpretativo previo.

\section{LA INTERPRETACIÓN SUSTANTIVA DE UNA RCA}

Tal como señala el profesor Patricio Zapata, en el Derecho "resulta imperativo identificar ciertas reglas, conocidas y ojalá compartidas, que reduzcan al mínimo posible los rangos de desacuerdo" ${ }^{46}$. En tales términos y más allá de los problemas y soluciones que pueda generar la interpretación de una norma jurídica, lo concreto es que una RCA es un acto administrativo de efectos particulares que autoriza el funcionamiento de una actividad sujeta al cumplimiento de ciertas normas y condiciones preestablecidas.

No obstante y a diferencia de otros actos administrativos cuyo contenido jurídico es más denso, en el caso de este tipo de actos su contenido está dado por aspectos técnicos y jurídicos, lo que implica, muchas veces, que su contenido deba ser interpretado, adicionalmente, por profesionales no afines, necesariamente, al Derecho.

Por lo tanto, considerando la disparidad de agentes (privados o públicos y formados en distintas disciplinas) que pueden, llegado el caso, interpretar una RCA, debe hacerse, en consecuencia, un esfuerzo por reducir los contornos de la interpretación de este tipo de instrumentos y fijar reglas coherentes que permitan, más allá de la tipología del proyecto o actividad, dar estabilidad para resolver aspectos indeterminados o dudosos de una RCA. Se requieren reglas que otorguen predictibilidad y permitan tener un canon o metodología interpretativa a la hora de dilucidar el sentido y alcance de una RCA bajo un prisma que reconozca como pilar fundamental el principio de la primacía de la realidad.

De esta forma, al garantizar la RCA derechos reconocidos en la propia CPR, tales como el derecho a desarrollar cualquier actividad económica (19 $\left.\mathrm{N}^{\circ} 21\right)$ y de propiedad (19 $\left.\mathrm{N}^{\circ} 24\right)$, permitiendo que los derechos que emanan de ella ingresen al patrimonio del titular, garantizando, además -vía SEIA y otros instrumentos de gestión ambiental-, la vigencia de otros, como el derecho a vivir en un medio ambiente libre de contaminación

46 Zapata (2002) p. 23. 
(19 $\mathrm{N}^{\circ}$ 8), no puede soslayarse que las reglas y principios interpretativos de la CPR y del derecho administrativo, en general, deben complementar esta labor dando pautas y criterios orientadores.

Por eso, la RCA, como todo acto administrativo, más allá de sus particularidades propias, debe interpretarse siempre desde y hacia el derecho público, quedando sujeta cualquier interpretación de su contenido a los estándares, principios y reglas que la CPR y el derecho administrativo disponen ${ }^{47}$.

No obstante, al margen de esta supletoriedad, la RCA tiene reglas de interpretación propias que la distinguen de otros actos administrativos, lo que obliga a fijar cuáles son esos criterios que, al margen de cualquier interpretación de autoridad como aquella contemplada en el artículo 81 letra g) de la ley, debe seguir todo intérprete en cualquiera de las modalidades que este trabajo describe. Dejamos constancia, eso sí, que en ningún caso se pretenden agotar en este artículo todos los criterios interpretativos propios de una RCA: simplemente se aspira a fijar un punto de partida sobre el cual fijar un marco que permita delimitar el ámbito sobre el que esta facultad debe ejercerse, ya habiendo explicado quién lo realiza (órgano) y cómo se ejecuta (procedimiento).

Lo descrito cobra mucha importancia, toda vez que se carece de una dogmática en el derecho ambiental que permita explicar adecuadamente el sistema vigente. Para ello, es necesario estandarizar una forma de interpretación que logre, al menos en una primera etapa, ordenar el mecanismo de interpretación de una RCA a fin de no caer en decisiones inconexas y contradictorias, resueltas en el caso a caso, pudiendo saber, todos (administración y administrados), con antelación el tratamiento jurídico que se va a recibir.

\subsection{Particularidades PROpias}

Considerando que una RCA es un acto administrativo de jerarquía inferior a la de una ley, lo dispuesto entre los artículos 19 al 24 del Código Civil puede aplicarse, pero con matices. En efecto, reconociendo que dichas reglas están plasmadas en una ley y que obligan a todos y a cada uno de los miembros de la comunidad nacional, sus criterios y orientaciones no pueden ser eludidos. En tales términos, y sin perjuicio de lo dispuesto en dichas normas, cinco criterios pueden ayudar, también, a cualquiera de las autoridades administrativas descritas (y también a los órganos jurisdiccionales correspondientes, en su caso), a determinar, genuinamente, el sentido y alcance de una RCA, orientando la forma en que estas deben ser entendidas en el caso concreto.

Lo anterior, en ningún caso desestima la importancia y el aporte que el elemento gramatical, histórico, lógico y sistémtico (o en su defecto la equidad natural o el espíritu general de la legislación) que el Código Civil contempla en los artículos citados, otorga. No obstante, estos elementos de interpretación constituyen una base que hace insuficiente,

47 Para un completo análisis respecto de criterios de interpretación jurídica en el derecho administrativo, véase CELIs (2009). Igualmente, debe señalarse que la CGR ha reconocido la aplicabilidad de las normas sobre interpretación de ley que el Código Civil contempla en sus artículos 19 al 24, al interpretar normas legales y administrativas, tal como lo reflejan los Dictámenes $N^{\circ} 37.355 / 2.013 ; 31.140 / 2.013 ; 26.799 / 2.013$; y 21.598/2012. Asimismo, la CGR ha dispuesto la forma en que dichos artículos deben ser usados al realizar cualquier ejercicio interpretativo de una norma jurídica (Dictamen $\mathrm{N}^{\circ} 29.505 / 2005$ ). 
a partir de las complejidades propias de una RCA, definir el verdadero sentido y alcance de estas. Por eso, para estos efectos, el aporte de Andrés Bello y de quienes ejercieron sobre él una influencia ${ }^{48}$, es un punto de inicio, pero no de término. Más allá de la separación y jerarquía que de estos cuatro elementos pueda hacerse, no puede soslayarse que la exposición que a continuación se hace, urde sus raíces en dichas reglas, las que además han sido reconocidas por la jurisprudencia de la Corte Suprema invariablemente ${ }^{49}$. Pese a eso, no debe olvidarse que el Tribunal Constitucional ya ha fijado, desde el año 2001, una distancia respecto de ellas ${ }^{50}$, constituyendo así, su propia jurisprudencia, parte de las razones que motivan este artículo y que explican que el derecho administrativo y el derecho ambiental (en particular, sus instrumentos de gestión) puedan tener autonomía en sus reglas a la hora de ser interpretadas sus fuentes.

Por lo tanto, considerando que el derecho administrativo (rama en la que debe insertarse el derecho ambiental) tiene normas y principios distintos que los del derecho común o civil, es que se hace necesario, en un tipo de acto administrativo que tiene notas distintivas respecto de otros (como lo es la RCA), fijar cánones de interpretación que la diferencien, pero que guarden, al mismo tiempo, al menos una lógica jurídica de interpretación, que permita ser identificada por quienes han recibido algún tipo de formación jurídica.

\section{a) Texto, contexto y finalidad}

No cabe duda que el texto de una RCA es fundamental. Sus palabras y su significado cabal cumplen un rol esencial. De allí que las palabras de uso corriente, legales y/o técnicas deban ser interpretadas en su significado correspondiente. Las primeras serán entendidas en sentido natural y obvio, cumpliendo el Diccionario de la Real Academia de la Lengua, al igual que cualquier texto jurídico, un rol insustituible. Las segundas, de acuerdo al sentido que el ordenamiento jurídico les da y aquellas palabras técnicas o de contenido científico, deberán ser interpretadas según el sentido de quienes profesan esa determinada ciencia u arte (biología, ingeniería, geografía, antropología, etc. ${ }^{51}$. La interpretación de una RCA no puede realizarse de espaldas al texto.

No obstante, aquello no es suficiente en una RCA. Sin perjuicio del uso recurrente de estos tres tipos de palabras, el análisis interpretativo debe incluir otros aspectos. Esa perspectiva, tal como lo recuerda Wróblewski, es necesaria ya que muchas "expresiones tomadas [in abstracto], sin ninguna referencia al contexto en el que son usadas resultan ambiguas o vagas, pero puestas en el contexto de su uso en esa situación dada, resultan lo suficientemente precisas como para transmitir información deseada, al menos en un determinado universo de discurso" ${ }^{52}$.

\footnotetext{
48 Véase GuZMÁn (1992) s/p.

49 Véase Andreucci (2008) s/p.

50 Sentencia del Tribunal Constitucional, Rol N³25, de 26 de junio de 2001, considerandos sexto, décimo, duodécimo y trigésimo.

51 Para una revisión de los conceptos técnico-jurídicos del derecho ambiental chileno, véase BERMúdEZ (2007) pp. 51-69.

52 Wróblewski (1963) p. 410; Massini (2004) p. 159.
} 
Así las cosas, el texto de una RCA al ser interpretado requiere, también, de un contexto, dado, generalmente, por el proyecto o actividad y su entorno. De esta forma, la etapa de desarrollo de este, su tamaño o su nivel de ejecución o cambio, en caso que haya sufrido modificaciones en relación a su diseño original, sean o no de consideración, son aspectos adicionales al texto que deben tenerse presente. De igual forma, si los componentes ambientales del proyecto (aire, agua y suelo) o los sistemas biológicos (flora, fauna y ecosistemas) han evolucionado de una forma distinta a la proyectada, más allá de los mecanismos legales para ajustar esa situación, la interpretación del texto requiere, además, considerar dichas variables y determinar si la letra y espíritu de la autorización permiten ajustarse, de manera flexible, a un cambio de circunstancias originalmente no previsto. Es más, en el caso de los EIA la línea de base pudo haber sufrido cambios de consideración que han hecho que el área de influencia haya variado sustancialmente, haciendo inaplicable, en principio, ciertas disposiciones o considerandos, lo que obliga, en una interpretación de buena fe y evolutiva, a considerar dicha situación.

Adicionalmente, entre muchos otros cambios, ocurre que ciertas normas legales y administrativas son modificadas. En iguales circunstancias, las autoridades de turno y las políticas y planes públicos a nivel nacional y regional sufren cambios. Esto lleva, naturalmente, a que los proyectos deban, al margen de su texto expreso, adecuarse a nuevos escenarios. Contextos que al margen de su dimensión jurídica, política, social y económica, obligan, a proyectos o actividades pensadas para varias décadas, a incorporar parte de dicho acervo en su realización, control y cumplimiento. En consecuencia, cambios en el sistema ambiental obligan, al momento de interpretar una RCA, a incorporar, dentro de dicho análisis, las alteraciones que el entorno ha tenido, todo con la finalidad de arribar a una solución razonable, proporcional y ajustada plenamente al principio preventivo que inspira a este y otros instrumentos de gestión ambiental que la ley reconoce en base a la tipología propia de cada proyecto o actividad.

Todo lo anterior requiere, a partir de la precariedad que el propio ambiente genera, identificar, analizar, medir y jerarquizar, convenientemente, todos los aspectos propios del contexto descrito con la finalidad de arribar a una interpretación que guarde relación con la finalidad propia del proyecto en razón de su tipología específica. No siendo así la RCA una autorización inmutable y con el objeto de adecuarse a todo lo dicho sin alterar la ingeniería básica o conceptual aceptada o aprobada, es que debe recurrirse, a fin dar una solución justa a una situación como la señalada, a la finalidad o descripción del proyecto mismo. Esa finalidad, condicionada por la información que el propio titular entregó al momento de evaluar el proyecto y que la autoridad ambiental consideró conforme, condiciona, finalmente, los límites sobre los cuales toda interpretación a una RCA debe efectuarse. En otras palabras: qué quiso o quiere, realmente, ejecutar el titular y bajo qué tipología contemplada en el artículo 10 de la ley, es lo que debe inspirar siempre cualquier interpretación a una RCA, pudiendo extraerse las restantes conclusiones (respecto al seguimiento, control y cumplimiento) a partir de ahí. Llevar la RCA a la vida presente a partir de sus propias disposiciones y en virtud de la finalidad que se tuvo en consideración al momento de diseñar el proyecto, es el primer desafío interpretativo que debe realizarse para sortear con éxito la ejecución evolutiva que todo proyecto padece. Eso obliga a considerar otras RCA que 
el proyecto tenga u otros cambios que haya sufrido que no hayan requerido su evaluación (resueltos vía pertinencia) y distinguir si se trata de una EIA o de una DIA, toda vez que las exigencias y deberes en uno u otro instrumento, varían.

\section{b) Procedimiento de evaluación}

Junto con el texto, contexto y la finalidad de un proyecto específico, en caso de duda respecto de una disposición expresa de una RCA, el procedimiento de evaluación y su posterior calificación, es decir, ese conjunto de actos trámites concatenados que le dan forma a la RCA, cumple un rol auxiliar relevante.

Para ello, podrá recurrirse al procedimiento de evaluación con la finalidad de desentrañar el sentido que algún servicio público pudo haber manifestado para que, por ejemplo, una determinada condición, exigencia o medida sea requerida para el funcionamiento de un proyecto. Conviene señalar que lo expuesto en una DIA o EIA y luego aclarado, por ejemplo, en la primera o segunda adenda respecto a la aplicabilidad de una norma, de un permiso ambiental sectorial (PAS) o en relación al inicio de las obras (expediente de seguimiento), se hace, muchas veces, indispensable para determinar los derechos y obligaciones que emanan de una RCA.

El proceso fidedigno de evaluación y calificación ambiental (que incluye también las actas de las sesiones de las Comisiones de Evaluación), se transforma, así, en un elemento útil y necesario, pero que jamás podrá reemplazar al texto, al margen de los errores que este pudiese tener. De existir errores de tipeo, numéricos, de referencia o de cálculos, existen otras vía para su solución (artículo 62 de la ley $\mathrm{N}^{\circ}$ 19.880). Así, en caso de querer desentrañar el sentido o finalidad de una RCA, este solo debe realizarse si el tenor de sus disposiciones y considerandos no es claro. Cumplirá, de esta forma, un aporte este elemento en la medida que esa revisión del procedimiento aporte luces que permitan, en el presente, aclarar un aspecto de la RCA. Es decir, no se recurre al procedimiento de evaluación sin razones o motivos que lo justifiquen: deben existir dudas en el texto, debidamente fundadas, para recurrir a esta herramienta auxiliar de interpretación. De recurrirse a este elemento, también debe realizarse una interpretación completa y omnicomprensiva de los aspectos que se quiera desentrañar, ya que es posible, incluso, advertir contradicciones y lagunas en el propio procedimiento que no permitan alcanzar el objetivo buscado.

Por eso, cuando el texto, contexto y finalidad de una RCA admite márgenes de duda y confusión, puede ser necesario revisar evidencia empírica (mediciones, estimaciones, tablas, modelaciones, etc.) que a veces se encuentran en documentos propios del procedimiento a fin de ilustrar un asunto de una RCA que arroja dudas. Para ello, deben ponderarse equilibradamente tanto los elementos de juicio aportados por la Administración del Estado como por el proponente y posterior titular del proyecto, pero teniendo siempre presente que recurrir a este vía debe hacerse prudentemente ya que también se puede incurrir en arbitrariedades e injusticias debido precisamente al carácter evolutivo que tienen las variables originalmente evaluadas años o décadas atrás ${ }^{53}$. No puede esterilizarse la labor de cualquier intérprete y eso debe ser cuidadosamente protegido a la hora que se revise la

53 En este sentido, Cordero Quinzacara (2010) p. 44. 
forma, el tiempo y los documentos que fueron elaborados al momento de evaluar y calificar un proyecto en el SEIA, ya que se recoge la manifestación de voluntad de la autoridad y del titular en una época determinada.

\section{c) Sistematicidad y funcionalidad}

Lo expuesto no se agota en los criterios anteriores. Lo importante, es, además, entender que las disposiciones de una RCA comparten, en general, un fin o un proceso productivo común que debe ser entendido en su totalidad. La trascendencia de lo anterior, es que todas las normas, medidas y condiciones exigidas para la ejecución de ese proceso productivo no solo están unidas entre sí, sino, además, deben permitir superar un excesivo formalismo y rigidez del que puede adolecer una RCA. Por eso, debe siempre interpretarse una RCA a partir de un todo que permita que sus disposiciones sean útiles ${ }^{54}$, funcionen, den vida a lo aceptado o aprobado. Es decir, que se interrelacionen dando soluciones justas que resguarden, como límite supremo, el derecho a vivir en un medio ambiente libre de contaminación.

Cualquier interpretación de una disposición de una RCA que lleve a una solución rígida que permita, por ejemplo, vulnerar una norma, de calidad o de emisión; un plan, de prevención o de descontaminación; o el objeto de protección de un área sujeta a protección oficial, debe ser desestimada de plano. Por eso, las disposiciones de una RCA deben tener un sentido útil, pero que sea armónico y guarde correspondencia con el resto de esta a partir de la protección de la biodiversidad; la conservación del patrimonio ambiental; el desarrollo sustentable; el aseguramiento de un medio ambiente libre de contaminación; la preservación de la naturaleza; y la protección del medio ambiente, todos conceptos que ley reconoce y define.

Por eso, ciertas disposiciones de una RCA deben servir para iluminar el sentido y alcance de otras. Lo anterior, siempre y en la medida que tampoco existan contradicciones entre ella, labor primordial que deberá cumplir la administración al dictar una RCA. En caso de existir dichas contradicciones en la RCA debe abandonarse este criterio, pues el sentido de este no es dar coherencia a la RCA, sino determinar el sentido de una disposición o considerando concreto cuya interpretación es confusa y dudosa en función de su texto expreso ${ }^{55}$. A lo que apuntamos es que en caso de existir disposiciones que tengan varios sentidos o significados, deberá tenerse presente siempre, de manera sistemática (considerando todos aquellos significados, comunes y/o técnicos), la naturaleza del proyecto y en consecuencia su tipología y la buena fe de quién lo desarrolla. En iguales términos, en caso que exista duda respecto al sentido de una regla en contraposición con otra de la RCA, debe optarse siempre por una interpretación pro ambiente o preventiva. En otras palabras,

\footnotetext{
54 En palabras de Celis no debe olvidarse el principio del efecto útil de cualquier interpretación, en términos que debe preferirse siempre aquellas en virtud de las cuales los preceptos produzcan un efecto útil, en desmedro de aquellas que los priven de eficacia, Celis (2009) p. 57.

55 Respecto de este aspecto, pero en materia de interpretación de la ley, véase RodríGuez (1995) p. 83.
} 
debe buscarse una interpretación que detenga o posponga "una acción previsiblemente lesiva", que pueda dañar el "ambiente de un modo relevante"56.

\section{d) Primacía de la realidad}

Habiendo descrito tres criterios que siguen un orden lógico y concatenado, no importando la modalidad de interpretación a la que se refieran, otro criterio importante constituye el interpretar una RCA desde la realidad. Es decir, interpretarla desde lo que efectivamente ha sido aceptado o aprobado y que finalmente ha ejecutado el titular. Lo expuesto se explica debido a que la RCA es insuficiente y limitada para abarcar un entorno que la sobrepasa. La RCA no es capaz de reflejar dentro de sí toda la complejidad de los ecosistemas ${ }^{57}$.

Lo dicho cobra mucho sentido, especialmente en materia de fiscalización y sanción debido a que debe constatarse in situ si las normas, condiciones y medidas de una RCA son cumplidas a cabalidad. Así, las actas de fiscalización o inspección, que constituyen actos administrativos y que generalmente manifiestan el ejercicio de las facultades de control y supervigilancia de los órganos de la Administración del Estado (incluida la SMA), constatan una realidad respecto de la cual existe, generalmente, una presunción de certeza y veracidad, pese a las fundadas críticas existentes ${ }^{58}$. Esta idea ha sido además reconocida por la CGR, la que ha señalado que la "fiscalización y la potestad sancionatoria deben ejercitarse con la debida racionalidad, en términos de que no pueden limitarse a una mera constatación formal entre la resolución de calificación ambiental y los hechos" 59 .

En idénticos términos, lo exigido precisamente mediante dichas normas, condiciones o medidas debe corresponder a la realidad de lo que es posible hacer de manera gradual (de manera moderada e incremental sin renunciar a un objetivo de largo plazo) y técnica (exigencia de la mejor tecnología disponible). Así, por ejemplo, a fin de determinar la compensación de $\mathrm{MP}_{10}$ o $\mathrm{NO}_{\mathrm{x}}$ requerida respecto de un proyecto que se modifica en la Región Metropolitana, es relevante determinar su "situación base" en conformidad al artículo 98 del Plan de Descontaminación de la Región Metropolitana (PPDA). Para ello, si el proyecto se encuentra en construcción, en ejecución o abandonado en relación al proyecto original, es esencial, pues en función de dichas emisiones (compensadas) podrá determinarse el delta que podrá ser exigido a fin de cumplir con el 150\% de compensación que el PPDA mandata. En tales términos, deberá probarse si efectivamente hay o no una ejecución material del proyecto en base a elementos de prueba que así lo acrediten, constituyendo así la realidad misma un elemento de prueba y de interpretación que desborda los propios márgenes de la $\mathrm{RCA}^{60}$.

\footnotetext{
56 LORENZETTI (2008) p. 147.

57 Véase Serrano en relación al principio de la insuficiencia del derecho ambiental, Serrano (2007) pp. 132134.

58 Véase Jara y Maturana (2009) p. 11.

59 Dictamen $N^{\circ} 34.021 / 2.003$.

${ }^{60}$ En un sentido contrario a lo que se ha venido diciendo, véase la sentencia del Tribunal Ambiental, de fecha 9 de agosto de 2013, recaída en los autos Rol No 4 - 2013, especialmente sus considerandos sexto y octavo.
} 


\section{e) Incertidumbre, riesgo y principios}

Si bien el texto de la ley no reconoce, expresamente, el principio preventivo, sí lo hace su mensaje al señalar que "mediante este principio, se pretende evitar que se produzcan los problemas ambientales" ${ }^{61}$. De esta forma, lo que está detrás de toda evaluación ambiental es la incertidumbre y ante ella, el principio preventivo exige que se adopten las medidas necesarias para prevenir que ocurra un daño o perjuicio mayor. No es un principio que esté orientado a reparar los daños o lesiones producidas, sino a prevenir y cautelar que aquello no suceda ${ }^{62}$.

Por eso, el SEIA pretende predecir de una forma más o menos precisa "los efectos que un proyecto o actividad puede provocar sobre el medio ambiente en cada una de sus etapas (construcción, operación y abandono)" ${ }^{63}$. Esa predicción se realiza sobre un ecosistema que se comporta de manera compleja, con múltiples interacciones. Al evaluar y luego calificar un proyecto o actividad, no existe la certeza absoluta respecto de cómo evolucionarán muchas de sus variables, lo cual puede acrecentarse o desaparecer posteriormente. Por lo tanto, una interpretación preventiva obliga a considerar una cierta inseguridad ambiental que siempre está latente, pero que se expresa de manera concreta en los permisos de relevancia ambiental ${ }^{64}$, los cuales también requieren un canon interpretativo sujeto a las lógicas descritas. Así, en toda actividad económica aceptada o aprobada por medio de una RCA se tolera una alteración al medio ambiente. Esa alteración, que la ley llama impacto, también lleva implícitamente un riesgo. Es decir, la probabilidad de que la población sufra un efecto adverso en función de la peligrosidad y exposición a una sustancia, objeto o situación, la que debe ser evaluada cualitativa y cuantitativamente, en términos de su magnitud, severidad y extensión. Ante ese riesgo, en caso que así lo genere un proyecto o actividad mediante un EIA al producir los efectos, características y circunstancias de la letra a) del artículo 11 de la ley, la interpretación de las normas (principalmente de calidad y de emisión) y las medidas (de mitigación o compensación) deben realizarse desde el enfoque preventivo. El hecho que se produzca un riesgo inexistente o se incremente el habido, obliga a interpretar toda norma, condición o medida de una RCA con la cautela restrictiva que ello implica en razón del bien jurídico en juego: la salud de la población. Por ende, la interpretación, por ejemplo, respecto a la superación de valores en una norma, la composición de un contaminante químico sea o no cancerígeno o la exposición a mezclas de contaminantes debe realizarse con prudencia y rigurosidad a partir del principio preventivo ${ }^{65}$, toda vez que resulta "más eficaz y eficiente para la gestión ambiental prever eventuales menoscabos o detrimentos, que posteriormente restaurarlos o repararlos" ${ }^{\prime 66}$.

\footnotetext{
${ }^{61}$ Mensaje de la ley $\mathrm{N}^{\circ} 19.300$.

${ }^{62}$ Este aspecto ha sido recogido por la jurisprudencia nacional, en particular, por la Excelentísima Corte Suprema, destacando, a modo ejemplar, las sentencias respecto de los siguientes proyectos: Cuervo (C.S. Rol 2463-2012), Bocamina II (C.S. Rol 3141-2012), Dunas de Concón (C.S. Rol 2138-2012), Castilla (C.S 19602012) y Portal Bicentenario (C.S Rol 598-2010).

63 GuZmán (2012) p. 130.

${ }^{64}$ Astorga (2000) p. 25.

65 Para mayor información, véase la Guía de Evaluación de Impacto Ambiental. Riesgo para la salud de la población (2012).

66 Astorga (2012) p. 14.
} 
Asimismo, ante disposiciones o considerandos ambiguos de una RCA que permitan dos o más interpretaciones posibles o en caso de duda o lagunas que esta adolezca, deben aplicarse los principios generales de la legislación ambiental. Así, no cabe duda que el principio preventivo infunde buena parte de nuestra legislación ambiental. En iguales términos, otros principios generales y también del derecho ambiental, pueden cumplir un rol esencial al dilucidar el sentido y alcance de aspectos dudosos de una RCA y de sus respectivas lagunas. Lo expuesto se funda en el hecho que los daños al medio ambiente son muchas veces irreversibles, catastróficos y continuos, lo que incluso permite, con mucha posterioridad, determinar si hay o no un daño, el que, muchas veces, puede ser imputable a distintas cau$\operatorname{sas}^{67}$.

Para ello, principios generales tales como el efecto "validante" que en ciertos y específicos casos procede atribuir al error común; la circunstancia de que nadie puede estar obligado a lo imposible (como ocurre con condiciones impuestas en una RCA que dependen de un tercero o circunstancias ajenas a la voluntad del titular y que se hacen imposible de cumplir $\left.{ }^{68}\right)$; la renunciabilidad de los derechos que solo miran el interés individual; la presunción de la buena fe (fraccionamiento); y el de proporcionalidad (la gravedad de la situación -impacto o infracción- debe guardar concordancia con las medidas o multas asociadas al cumplimiento de una RCA $)^{69}$ pueden ayudar a resolver muchas de las imprecisiones que presente una RCA. Lo anterior, por su puesto, teniendo presente que son los principios de derecho ambiental los que primero deben usarse, los que en el caso del SEIA tienen particular aplicación, esencialmente el principio preventivo, el de gradualidad, el de la responsabilidad, el participativo, el de eficiencia, el de "ventanilla única", entre otros ${ }^{70}$.

\section{CONCLUSIONES}

De todo lo señalado, es posible concluir que al momento de interpretar una RCA existen distintas modalidades que exceden a lo dispuesto en el artículo 81 letra g) de la ley. Para ello, la ley ha estructurado órganos a cargo de dicha interpretación y procedimientos al efecto, los que varían dependiendo del tipo de modalidad interpretativa. Junto con dichas dimensiones, la interpretación de una RCA debe responder no solo al quién y al cómo se interpreta, sino además debe estar sujeta a una dogmática que permita fijar criterios más o menos generales para definir la interpretación sustantiva de una RCA. Para ello, y como punto de partida, se pueden considerar los cinco criterios que este artículo propone, los

\footnotetext{
${ }^{67}$ Véase Lazaruz $(2000) \mathrm{s} / \mathrm{p}$. En iguales términos, ha ido razonando el Segundo Tribunal Ambiental respecto de la "Central Huilo Huilo" al adoptar medidas provisionales y señalar expresamente que al no contarse con RCA, "impide determinar los impactos ambientales que puede producir la ejecución del proyecto y hace suponer a este Tribunal la existencia de un riesgo inminente de daño al medio ambiente que es necesario prevenir", Rol No $\mathrm{N}-1-2013$.

${ }^{68}$ Estas condiciones constituyen un ejemplo de una obligación potestativa, toda vez que no depende del hecho voluntario del titular, sino que de un tercero ajeno al proyecto respectivo. Véase VIAL (2007) pp. 49-53.

69 Véase Alcalde (2003) pp. 58-67 y p. 192.

70 Para Schmidt-Assmann existen otros principios también relevantes, tales como el de precaución, el de cooperación y de quién contamina paga, SchmidT-Assmann (2003) pp. 132-134.
} 
cuales, ayudan definir los contornos referidos a este acto administrativo, tal como ocurre en otros ámbitos de la legislación nacional.

\section{BIBLIOGRAFÍA CITADA}

Alcalde Rodríguez, Enrique (2003): Los principios generales del derecho. Su función de garantía en el derecho público y privado chileno (Santiago, Ediciones Universidad Católica de Chile) 278 pp.

Andreucci Aguilera, Rodrigo (2008): "Los conceptos de la Corte Suprema sobre interpretación de la ley a través de sus sentencias", en: Revista Nomos - Universidad de Viña del Mar, $\mathrm{N}^{\circ}$ 1: pp. 11-39.

Aróstica Maldonado, Iván (1986): "La motivación de los actos administrativos en el derecho chileno", en: Revista de Derecho de la Pontificia Universidad Católica de Valparaiso, Vol. X: pp. 499-520.

Astorga Jorquera, Eduardo (2000): Sistema de Evaluación de Impacto Ambiental. Régimen Jurídico en Especial Aplicado a la Actividad Minera (Santiago, Editorial Jurídica ConoSur Ltda.) 527 pp.

Astorga Jorquera, Eduardo (2012): Derecho Ambiental Chileno. Parte General (Santiago, Abeledo Perrot-Thomson Reuters, tercera edición actualizada) 402 pp.

Bermúdez Soto, Jorge (2007): Fundamentos de Derecho Ambiental (Valparaíso, Ediciones Universitarias del Valparaíso, Pontificia Universidad Católica de Valparaíso) 285 pp.

Bermúdez Soto, Jorge (2011): Derecho Administrativo General (Santiago, Abeledo PerrotThomson Reuters, segunda edición actualizada) 603 pp.

Bermúdez Soto, Jorge (2013): "Fundamentos y límites de la potestad sancionadora administrativa en materia ambiental", en: Revista de Derecho de la Pontificia Universidad Católica de Valparaíso, XL: pp. 421-447.

Bordalí Salamanca, Andrés (2004): Tutela Jurisdiccional del Medio Ambiente (Valdivia, Editorial Fallos del Mes), 485 pp.

Camacho Cépeda, Gladys (2005): "La problemática de la potestad normativa de las Superintendencias", en: Actas XXXIV Jornadas de Derecho Público: pp. 423-432.

Celiz Danzinger, Gabriel (2009): "La interpretación jurídica en el derecho administrativo contemporáneo", en: Revista Nomos - Universidad de Viña del Mar, No 3: pp. 41- 81.

Cordero Quinzacara, Eduardo (2010): "Las normas administrativas y el sistema de fuentes”, en: Revista de Derecho Universidad Católica del Norte, Año 17 Nº 1: pp. 21-50.

Cordero Vega, Luis (2013): "Interpretación de las Resoluciones de Calificación Ambiental”, en El Mercurio Legal, disponible en: http://www.elmercurio.com/Legal/Noticias/ Analisis-Juridico/2013/04/25/Interpretacion-de-las-Resoluciones-de-Calificacion-Ambiental. aspx [fecha de consulta: 22 de julio de 2013].

Díaz de Valdés Julia, José Manuel (2010): “Anomalías Constitucionales de las Superintendencias: un diagnóstico”, en: Estudio Constitucionales, Año 8: pp. 249-282.

Escuín Palop, Vicente y Belando Garín, Beatriz (2011): Los recursos administrativos (Navarra, Civitas) pp. 42. 
García García, José Francisco (2009): “'Inflación de superintendencias? Un diagnóstico crítico desde el derecho regulatorio”, en: Revista Actualidad Jurídica, № 19, Tomo I: pp. 327-372.

GuZMÁn BRITO, Alejandro (1992): "La historia dogmática de las normas sobre interpretación recibidas por el Código Civil de Chile", en: Interpretación, integración y razonamiento jurídicos (Santiago, Editorial Jurídica de Chile, pp. 41-87.

Guzmán Rosen, Rodrigo (2012): Derecho Ambiental Chileno. Principios, instituciones, instrumentos de gestión (Santiago, Planeta Sostenible) 267 pp.

Jara Schnettler, Jaime y Maturana Miquel, Cristian (2009): “Actas de fiscalización y debido procedimiento administrativo", en: Revista de Derecho Administrativo. Doctrina. Legislación. Jurisprudencia. $\mathrm{N}^{\circ}$ 3: pp. 1-28.

LazaruZ, Richard J. (2000): "Restoring What's Environmental About Environmental Law in the Supreme Court", University of California, Los Angeles, Law Review N ${ }^{\circ}$ 47: pp. 703-812.

LorenzetTI, Ricardo Luis (2008): Teoría del Derecho Ambiental (Santiago, La Ley) 291 pp.

Nieto García, Alejandro (2012): Derecho Administrativo Sancionador (Santiago, Editorial Tecnos, quinta edición totalmente reformada) $611 \mathrm{pp}$.

Parejo Alfonso, Luciano (2012): Lecciones de Derecho Administrativo (Santiago, Editorial Tirant lo Blanch) 990 pp.

Prieto Pradenas, Magdalena (2013): "Las consultas de pertinencias de ingreso al Sistema de Evaluación de Impacto Ambiental como herramienta de flexibilización acto administraivo ambiental", en: Revista de Derecho Administrativo. Doctrina. Legislación. Jurisprudencia, $N^{\circ}$ 8: pp. 181-196.

Rodríguez Grez, Pablo (1992): Teoría de la interpretación jurídica (Santiago, Editorial Jurídica. Colección Manuales Jurídicos) 182 pp.

Sánchez Morón, Miguel (2012): Derecho Administrativo Parte General (Santiago, Editorial Tecnos, octava edición) $954 \mathrm{pp}$.

Serrano Moreno, José Luis (2007): Principios de derecho ambiental y ecología jurídica (Santiago, Editorial Trotta) 165 pp.

SCHMidT-Assmann, Eberhard (2003): La teoría general del derecho administrativo como sistema. Objeto y fundamentos de la construcción sistemática (Madrid, Marcial Pons) 475 pp.

Sото Kloss, Eduardo (1993): "En la forma que prescriba la ley. Notas sobre prácticas legislativas inconstitucionales", en: Revista Chilena de Derecho, XXIV Jornadas de Derecho Público, Vol. 20. No 2 -3: pp. 687-693.

Soto Kloss, Eduardo (2013): Derecho Administrativo. Temas Fundamentales (Santiago, Editorial Abeledo Perrot) $966 \mathrm{pp}$.

Wróblewski, Jerzy (1963): Semantic Basis of the Theory of Legal Interpretation. Louvain - Paris, 410 pp., en Massini Correas, Carlos L (2004): Determinación del derecho y directivas de la interpretación jurídica. Revista Chilena del Derecho, Vol. $31 \mathrm{~N}^{\circ}$ 1: pp. 155 $-168$.

Vial Del Río, Víctor (2007): Manual de las obligaciones en el Código Civil Chileno (Santiago, Biblioteca Americana, segunda edición renovada y ampliada) 434 pp. 
Zapata Larraín, Patricio (2002): La Jurisprudencia del Tribunal Constitucional. Parte General (Santiago, Biblioteca Americana) 200 pp.

\section{JURISPRUDENCIA CITADA}

Sentencia de la Corte Suprema, Rol N 10. 220 - 2011, de 4 de abril de 2011. Disponible en http://www.poderjudicial.cl [Fecha de consulta: 23 de julio 2013].

Sentencia de la Corte Suprema, Rol No 2.463 - 2012, de 11 de mayo de 2012. Disponible en http://www.poderjudicial.cl [Fecha de consulta: 23 de julio 2013].

Sentencia de la Corte Suprema, Rol No 3.141 - 2012, de 15 de junio de 2012. Disponible en http://www.poderjudicial.cl [Fecha de consulta: 23 de julio 2013].

Sentencia de la Corte Suprema, Rol No 2.138 - 2012, de 27 de julio de 2012. Disponible en http://www.poderjudicial.cl [Fecha de consulta: 23 de julio 2013].

Sentencia de la Corte Suprema, Rol No 1.960 - 2012, de 28 de agosto de 2012. Disponible en http://www.poderjudicial.cl [Fecha de consulta: 23 de julio 2013].

Sentencia de la Corte Suprema, Rol No 598 - 2012, de 30 de noviembre de 2012. Disponible en http://www.poderjudicial.cl [Fecha de consulta: 23 de julio 2013].

Sentencia de la Corte Suprema, Rol No 8 - 2013, de 26 de marzo de 2012. Disponible en http://www.poderjudicial.cl [Fecha de consulta: 23 de julio 2013].

Sentencia de la Corte Suprema, Rol No 3.918 - 2012, de 2 de mayo de 2013. Disponible en http://www.poderjudicial.cl [Fecha de consulta: 23 de julio 2013].

Sentencia de la Corte Suprema, Roles Nos 7861-2013 y 9012-2013, de 14 de enero de 2014. Disponible en http://www.poderjudicial.cl [Fecha de consulta: 24 de enero 2014].

Sentencia de la Corte de Apelaciones de Temuco, Rol No 2162-2013, de 13 de septiembre de 2013. Disponible en http://www.poderjudicial.cl [Fecha de consulta: 30 de septiembre 2013].

Sentencia del Segundo Tribunal Ambiental de Santiago, Rol No $4-2013$, de 9 de agosto de 2013. Disponible en http://tribunalambiental.cl/2ta/ [Fecha de consulta: 30 de septiembre 2013].

Sentencia del Tribunal Constitucional, Rol No 325 - 2001, de 26 de junio de 2001. Disponible en http://www.tribunalconstitucional.cl/wp [Fecha de consulta: 27 de septiembre de 2013].

Dictamen de la Contraloría General de la República N 62.223/2013. Disponible en http://www.contraloria.cl [Fecha de consulta: 14 de enero de 2014].

Dictamen de la Contraloría General de la República N³7.355/2013. Disponible en http://www.contraloria.cl [Fecha de consulta: 23 de julio de 2013].

Dictamen de la Contraloría General de la República No 31.140/2013. Disponible en http://www.contraloria.cl [Fecha de consulta: 23 de julio de 2013].

Dictamen de la Contraloría General de la República No 26.799/2013. Disponible en http://www.contraloria.cl [Fecha de consulta: 23 de julio de 2013].

Dictamen de la Contraloría General de la República No 38.581/2013. Disponible en http://www.contraloria.cl [Fecha de consulta: 23 de julio de 2013]. 
Dictamen de la Contraloría General de la República N 7.620/2013. Disponible en http:// www.contraloria.cl [Fecha de consulta: 23 de julio de 2013].

Dictamen de la Contraloría General de la República No 50.596/2012, confirmado por el dictamen $\mathrm{N}^{\circ} 15.001 / 2013$. Disponible en http://www.contraloria.cl [Fecha de consulta: 23 de julio de 2013].

Dictamen de la Contraloría General de la República N ${ }^{\circ} 80.276 / 2012$. Disponible en http://www.contraloria.cl [Fecha de consulta: 23 de julio de 2013].

Dictamen de la Contraloría General de la República No 21.598/2012. Disponible en http://www.contraloria.cl [Fecha de consulta: 23 de julio de 2013].

Dictamen de la Contraloría General de la República N ${ }^{\circ} 29.505 / 2005$. Disponible en http://www.contraloria.cl [Fecha de consulta: 23 de julio de 2013].

Dictamen de la Contraloría General de la República N ${ }^{\circ} 34.021 / 2003$. Disponible en http://www.contraloria.cl [Fecha de consulta: 23 de julio de 2013].

Resolución del Segundo Tribunal Ambiental de Santiago, Rol No S - $1-2013$, de 25 de junio de 2013. Disponible en http://tribunalambiental.cl/2ta [Fecha de consulta: 23 de julio de 2013].

\section{NORMAS CITADAS}

\section{Constitución Política de la República de Chile.}

LEY N ${ }^{\circ} 19.300$, sobre Bases Generales del Medio Ambiente.

Ley $N^{\circ} 19.880$, sobre bases del procedimiento de los actos de los órganos de la Administración del Estado.

LEY N ${ }^{\circ} 20.417$, crea el Ministerio, el Servicio de Evaluación Ambiental y la Superintendencia del Medio Ambiente.

Ley N ${ }^{\circ}$ 18.575, Orgánica Constitucional de Bases Generales de la Administración del Estado.

LEY $N^{\circ} 18.410$, que crea la Superintendencia de Electricidad y Combustibles.

Decreto Supremo No 95/2001, Reglamento del Sistema de Evaluación de Impacto Ambiental.

\section{OTRAS FUENTES}

Guía de Evaluación de Impacto Ambiental. Riesgo para la Salud de la Población (2012). Servicio de Evaluación Ambiental, 47 pp.

ORD. N ${ }^{\circ} 131.456$, de la Dirección Ejecutiva del SEA, de 12 de septiembre de 2013, que "Imparte instrucciones sobre las consultas de pertinencia de ingreso al Sistema de Evaluación de Impacto Ambiental”. Disponible en http://www.sea.gob.cl [Fecha de consulta: 30 de septiembre de 2013].

Ord. $N^{\circ}$ 131.049, de la Dirección Ejecutiva del SEA, de 1 de julio de 2013, que Modifica "Instructivo sobre las consultas de pertinencia de ingreso al Sistema de Evaluación de Impacto Ambiental”. Disponible en http://www.sea.gob.cl [Fecha de consulta: 30 de septiembre de 2013]. 
Mensaje de la Ley $\mathrm{N}^{\circ} 19.300$.

Procedimiento referido a la revisión de la RCA del proyecto Convento Viejo. Disponible en http://www.sea.gob.cl [Fecha de consulta: 23 de julio de 2013]. 
